Mestizaje colonial y mestizajes estratégicos. Una mirada crítica a la relación entre historia regional e historia indígena.

Manuel Fontenla

Anuario № 30 / ISSN 1853-8835 / pp. 11-44 /2018

http://anuariodehistoria.unr.edu.ar/ojs/index.php/Anuario/index

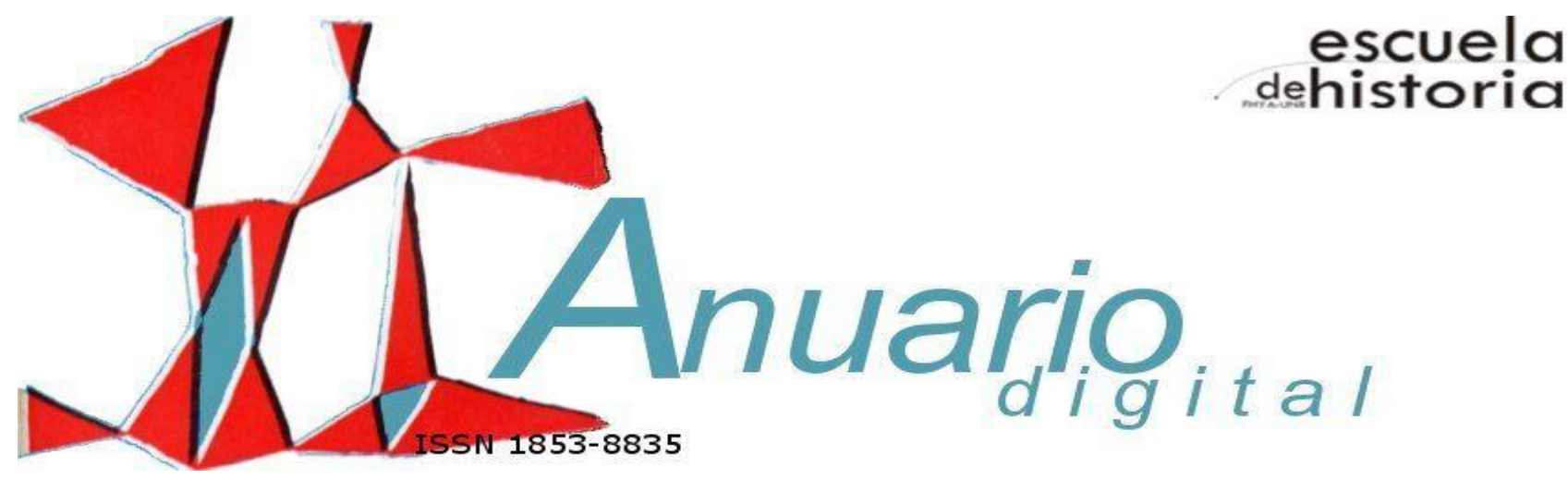

\title{
Mestizaje colonial y mestizajes estratégicos. Una mirada crítica a la relación entre historia regional e historia indígena
}

\section{Colonial miscegenation and strategic mestizajes. A critical look at the relationship between regional history and indigenous history}

MANUEL FONTENLA*

(Universidad Nacional de Catamarca - Consejo Nacional de Investigaciones

Científicas y Técnicas); Argentina

manuruzo@gmail.com

RESUMEN

En el imaginario racial de la historiografía nacional argentina, tanto la del Siglo XIX como la del XX, el mestizaje fue uno de los ejes principales que estructuró el discurso de blanqueamiento y la "desaparición/extinción" de las sociedades indígenas. En un resumen abrupto y simplificador, pero no menos cierto, podría decirse que en estos registros históricos predominó un borramiento deliberado de la

\footnotetext{
* Prof. Adjunto a cargo de la Cátedra de Pensamiento Indígena y Latinoamericano, depto. Filosofía, Universidad Nacional de Catamarca. Becario doctoral, CONICET, Instituto de Humanidades, Universidad Nacional de Córdoba.
}

Esta obra está sujeta a la Licencia Reconocimiento-NoComercial-Compartirlgual 4.0 Internacional de Creative Commons. http://creativecommons.org/licenses/by-nc-sa/4.0/ 
historia indígena, de su agencia, de su presencia y de su devenir histórico. En la actualidad, algunas perspectivas críticas del colonialismo han avanzado en la descripción de estos imaginarios y sus lógicas históricas de saber/poder, y entre ellos, de la función que cumplió el mestizaje como discurso ideológico (blanqueador y patriarcal) y como imaginario racial en ese borramiento histórico. Pero muy pocas investigaciones se han focalizado sobre estos mismos aspectos en las historiografías regionales, y mucho menos aún, en la relación entre ese pasado indígena negado e invisibilizado, y la actual historia regional. Para contrarrestar estas ausencias, y explorar estas relaciones, propongo una relectura del mestizaje, que no sea reductible necesariamente a la idea de un discurso ideológico de homogeneización y blanqueamiento, sino que, a modo de una categoría de pivoteo, nos permita mirar tanto la historia regional como la historia indígena desde una perspectiva diferente.

Palabras clave: Mestizaje colonial; mestizajes estratégicos; historia regional; historia indígena.

ABSTRACT:

In the racial imaginary of Argentina's national historiography, both that of the 19th and 20th centuries, miscegenation was one of the main axes that structured the whitening discourse and the "disappearance/extinction" of indigenous societies. In an abrupt and simplifying summary, but no less true, one could say that in these historical records a deliberate effacement of indigenous history, its agency, its presence and its historical evolution prevailed. At present, some critical perspectives of colonialism have advanced in the description of these imaginaries and their historical logics of knowledge/power, and among them, of the role played by miscegenation as ideological discourse (bleach and patriarchal) and as racial imaginary in that historical effacement. But very few investigations have focused on these same aspects in regional historiographies, and much less, in the relationship between that denied and invisible indigenous past, and the current regional history. To counteract these absences, and explore these relationships, I propose a rereading of miscegenation, which is not necessarily reducible to the idea of an ideological discourse of homogenization and bleaching, but rather, as a category of pivoting, allows us to look at both the history regional as the indigenous history, from a different perspective.

Keywords: Colonial miscegenation; strategic mestizajes; regional history; indigenous history.

\section{Introducción}

En el imaginario racial de la historiografía nacional argentina, tanto la del Siglo XIX como la del XX, el mestizaje fue uno de los ejes principales que estructuró el discurso de blanqueamiento y la "desaparición/extinción" de las sociedades indígenas. En un resumen abrupto y simplificador, pero no

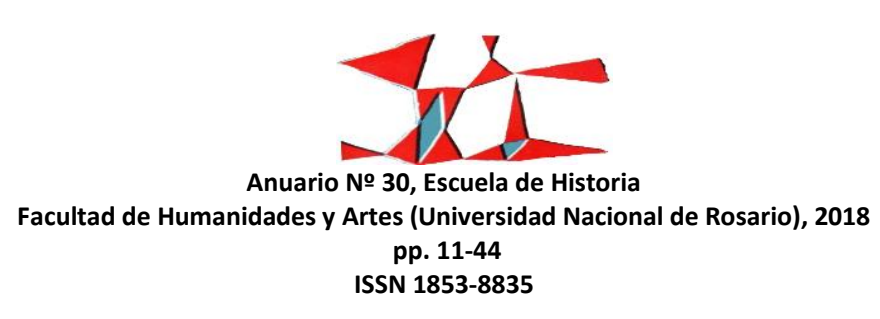




\section{Mestizaje colonial y mestizajes estratégicos. Una mirada crítica a la relación entre historia regional e historia indígena}

menos cierto, podría decirse que en estos registros históricos predominó un borramiento deliberado de la historia indígena, de su agencia, de su presencia y de su devenir histórico. En la actualidad, algunas perspectivas críticas del colonialismo ${ }^{1}$ han avanzado en la descripción de estos imaginarios y sus lógicas históricas de saber/poder, y entre ellos, de la función que cumplió el mestizaje como discurso ideológico (blanqueador y patriarcal) y como imaginario racial en ese borramiento histórico. En esta línea contamos con varios estudios críticos sobre las historiografías nacionales ${ }^{2}$, sobre todo en relación a la crítica de los procesos de homogeneización del Estado-nación que se dieron en los siglos XIX y XX en Latinoamérica. Pero muy pocas investigaciones se han focalizado sobre estos mismos aspectos en las historiografías regionales, y mucho menos aún, en la relación entre ese pasado indígena negado e invisibilizado, y la actual historia regional. Para contrarrestar estas ausencias y explorar estas relaciones propongo una relectura del mestizaje, que no sea reductible necesariamente a la idea de un discurso ideológico de homogeneización y blanqueamiento, sino que, a modo de una categoría de pivoteo, nos permita mirar tanto la historia regional como la historia indígena, desde una perspectiva diferente.

El imaginario racial del mestizaje expresado en la "Historia oficial" de nuestro estado-nación argentino, ha sido fundamental en la visión simplista y reduccionista que se construyó sobre los procesos de transformaciones vividos por las sociedades indígenas. Por ello, y frente a ello, el objetivo de este artículo, es problematizar dos sentidos del mestizaje que nos permitan disputar esas visiones simplistas y reduccionistas

\footnotetext{
${ }^{1}$ Mezzadra, S. (et al) Estudios postcoloniales: ensayos fundamentales; Madrid; Traficantes de sueños; 2008. Prakash, G. Postcolonial criticism and Indian historiography. Social Text, (31/32); p- 8-19; 1992. Barragán, R., \& Rivera Cusicanqui, S. Debates postcoloniales. Una introducción a los Estudios de la Subalternidad SIERPE; La Paz, pp.33-72; 1997. Chakrabarty, Dipesh, Al margen de Europa. Pensamiento poscolonial y diferencia histórica; Barcelona; Tusquets, 2008. Mallon, Florencia; "Promesa y dilema de los Estudios Subalternos: perspectivas a partir de la historia latinoamericana", Convergencia de Tiempos. Estudios subalternos / contextos latinoamericanos. Estado, cultura, subalternidad; Ámsterdam, Atlanta; EEUU; Rodopi; 1995. Dube Saurabh; Pasados Poscoloniales. Colegio de México; D.F. México; 1999. Bidaseca, K. Perturbando el texto colonial. Los Estudios (Pos) coloniales en América Latina, Editorial SB; Bs. As; 2010. Liendo, María Cristina; Criticas a la Modernidad en la Filosofía. Latinoamericana; UNC Editora; Córdoba; 2008. Mignolo, W. (et. Al.) Capitalismo y geopolítica del conocimiento; Buenos Aires; Ediciones del Signo; 2001. Fernández Nadal E, (s/f). Los estudios poscoloniales y la agenda de la filosofía latinoamericana actual en Revista Herramienta; Bs. As; Argentina.

2 Red de Investigadorxs en Genocidio y Pueblos Originarios (2017) "En el país de no me acuerdo. Archivos y memorias del genocidio del estado argentino sobre los pueblos originarios (1870-1950)"; Río Negro; Editorial UNRN; Mandrini, R. J. ;2013; "La historiografía argentina, los pueblos originarios y la incomodidad de los historiadores"; Quinto sol, 11; 19-38, Autónoma de México; UNAM. Anderson, B, Comunidades Imaginadas. Reflexiones sobre el origen y la difusión del nacionalismo; Fondo de Cultura Económica, México; 1993.Bhabha, H, (comp.); Nación y Narración; Siglo XXI editores; Buenos Aires; 2010. Devoto, F (comp.); La historiografía Argentina en el Siglo XX; Editores de América Latina; Buenos Aires. ACHA, O, Historia critica de la historiografía argentina; Vol. 1: Las izquierdas en el siglo XX; Prometeo; Buenos Aires; 2009.Biagini, H,- Roig, A, (dirs); El pensamiento alternativo en la argentina del Siglo XX; Tomo I y II; Biblos; Buenos Aires; 2006. Devoto, F., Pagano, N.; Historia de la historiografía Argentina; Sudamericana; Buenos Aires; 2009.
}

13

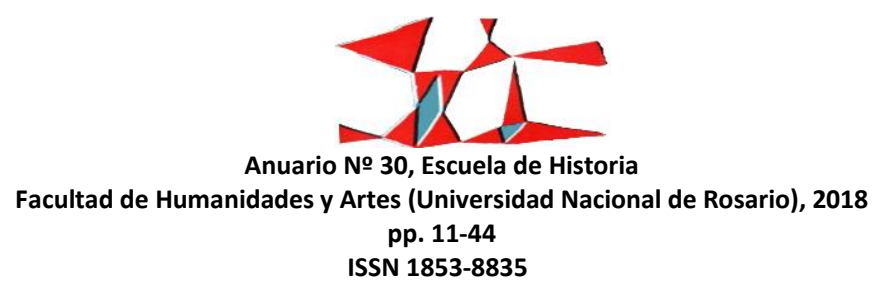


de los procesos históricos, identitarios y políticos de las sociedades indígenas. El primer registro, responde a lo que llamaré el mestizaje colonial, y nos servirá para mostrar cómo funciona el discurso ideológico del blanqueamiento y la homogeneización, pero ya no en la historiografía nacional, sino en la historiografía regional. El segundo sentido, que propongo llamar "mestizajes estratégicos" nos permitirá problematizar en el registro de la etnohistoria y la antropología cultural cómo algunos mestizajes han colaborado en la persistencia y reproducción de identidades que se enuncian y posicionan desde la cultura y la historia indígena. Veremos cómo estos discursos críticos de la colonialidad han pensado el mestizaje, la hibridez y la transculturación como espacios ambiguos de resistencia que pueden aportar a la construcción de futuras historias indígenas, al mismo tiempo que aportar elementos para la crítica de las historiografías nacionales y regionales.

\section{El mestizaje colonial en la historiografía regional del Noroeste Argentino}

Como he mencionado en la introducción, si bien contamos con investigaciones y estudios críticos sobre las historiografías nacionales, los mismos escasean sobre las historiografías regionales y provinciales. Atendiendo a lo que permite la extensión de un artículo, analizare como caso ejemplar Historia del Noroeste Argentino de Armando Raúl Bazán (1985)³ , libro emblema de la historiografía regional del NOA. Más allá del carácter canónico de este texto, lo he seleccionado porque justamente, el mismo autor propone en sus líneas centrales la idea de una matriz-étnica de mestizaje como factor central para entender la historia de la región y del país.

Pero antes de comenzar con dicho análisis, conviene sentar algunas referencias y características del devenir de esta corriente histórica. Existe una amplia bibliografía académica sobre la Historia Regional como abordaje especifico, donde se han tratado largamente discusiones en torno al concepto de región, a las dimensiones micro y macro, a su relación con la historia nacional, a sus recortes espaciales y temporales,

\footnotetext{
${ }^{3}$ La figura del historiador Armando Raúl Bazán es de un carácter representativo por muchas razones. En su prestigiosa trayectoria nacional e internacional puede contarse ser Miembro de la carrera de investigador del CONICET, Miembro de número de la Academia Nacional de la Historia, Miembro de las Academias de Historia de España, Perú, Bolivia, Paraguay, Uruguay, Brasil, Puerto Rico, Guatemala y Colombia; y Director del Centro de Investigaciones Históricas del Noroeste Argentino en la Universidad Nacional de Catamarca. Esta última función señala la importancia que ha tenido su concepción historiográfica en la conformación de carreras, líneas de investigación e investigadores en la región. En la tesis de doctorado, de la cual este artículo es una parte, analizo otras obras de Bazán, incluido uno de los últimos trabajos publicados por el Centro de Investigaciones Históricas del NOA, cuyo título es La Cultura del Noroeste Argentino; 2000; y en el cual se enfatizan y explicitan muchos de los aspectos que aquí señalaremos sobre su obra y su concepción historiográfica.
}

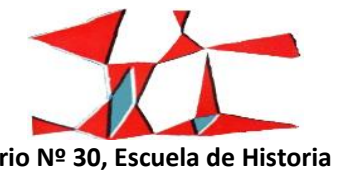

Facultad de Humanidades y Artes (Universidad Nacional de Rosario), 2018

pp. 11-44

ISSN 1853-8835 
Mestizaje colonial y mestizajes estratégicos. Una mirada crítica a la relación entre historia regional e historia indígena

sus autores y metodologías, etc. No es objeto de este estudio adentrarse en estas discusiones; me interesa más bien, comprender la autopercepción de estos historiadores sobre su labor y la visión de la historia que les interesaba disputar. Por eso, a modo de introducción, revisaré algunas afirmaciones del propio Armando Bazán, en un capítulo dedicado a la historiografía regional del NOA, publicado en uno de sus más recientes trabajos, La cultura del noroeste argentino del año 2000. En esta compilación encontramos un interesante capítulo, titulado "las ciencias del hombre", donde se revisa la historia provincial de Catamarca y la historiografía regional. Allí se aborda "la obra de quienes cultivaron en nuestra región las ciencias del pasado que tienen al hombre como protagonista. Ese quehacer tiene importancia primordial en la región fundadora de la nacionalidad, a la que hemos llamado la "matriz político-social de la argentina"4. Esta es una idea central de Bazán que también hace de eje en Historia del NOA, la matriz político social de la argentina, tiene su inicio y fundamento en nuestra región, más precisamente, en la formación del Tucumán Colonial. Pero veamos antes cómo entiende Bazán el trabajo de estos importantes hombres que cultivaron la historia. En el primer apartado, titulado "Los fundadores de la historiografía regional", se recupera la obra de Joaquín Carrillo iniciador de la historia provincial de Jujuy, la obra de Groussac para la provincia de Tucumán, la de Bernardo Frías para la historia de Salta, los estudios de Baltazar Olaechea y Alcorta para Santiago del Estero, y por supuesto de Samuel Lafone Quevedo para Catamarca. Si bien alguno de estos autores trabaja el periodo colonial (Lafone Quevedo destacadamente), lo que guía estas historias es el leitmotiv recién mencionado, "Frías propone una original versión de la historia nacional desde la perspectiva norteña y haciendo eje en la personalidad de un héroe, Martín Güemes"5 para Olaechea y Alcorta "ninguna obra Historia Argentina hacía mención del rol que a su provincia le cupo en el desarrollo progresivo del país" ${ }^{\prime \prime}$ y contra ello apunta su Crónica y Geografía de Santiago del Estero. El eje de esta recuperación, de estas lecturas que hace Bazán, revela uno de los sentidos principales de toda la historiografía regional del siglo XX, la falta de reconocimiento del aporte de las provincias a la historia nacional, este es su leitmotiv. Como lo muestran los estudios que cita Bazán, la historiografía regional del NOA buscó principalmente reposicionar la participación y "el aporte" de las provincias en la historia nacional, y no una búsqueda de las formas propias en que se podía pensar la historicidad de la región.

\footnotetext{
4 Bazán; 1995; p.71.

5 Bazán; 1995; p.73.

${ }^{6}$ Bazán; 1995; p.74.

15
}

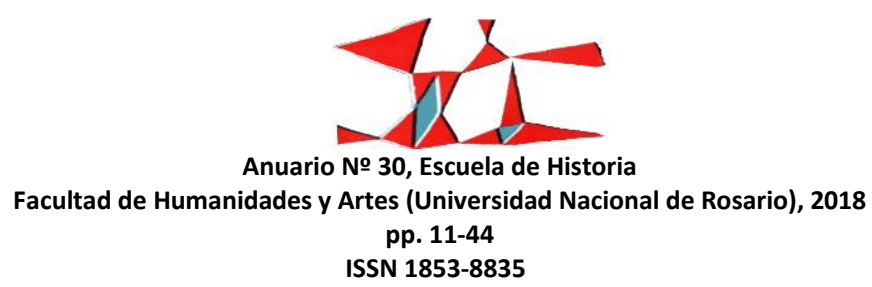


Teniendo en cuenta esto, sostengo que la revisión crítica de las historiografías y sus imaginarios raciales debe ser enfocada bajo una doble tarea crítica y una distinción importante. Por un lado, crítica y revisión de una historiografía fundacional nacionalista (criolla-urbana-burguesa-liberal); y por otro, crítica también de una historiografía regional de significación gaucha-provinciana-federal-popular, anclada en una idea de rescate del pasado histórico. Y si bien ambas están definidas por un carácter colonial frente al pasado indígena, y en ambas encontramos el discurso ideológico del mestizaje como blanqueamiento y extinción de los indios, también encontramos que este borramiento/olvido ha tomado diferentes formas y lógicas historiográficas que importa señalar y poner de relieve. Y parte de esas diferencias, se ha jugado en los discursos del mestizaje que no han sido ni unívocos ni contingentes, sino que por el contrario han dado lugar a diversas respuestas frente a las lógicas de la colonialidad. En busca de esas respuestas, la hipótesis de este artículo para una lectura crítica sobre la historiografía regional afirma que, si en la historiografía nacionalista se opera una total exclusión del pasado indígena, en la historiografía regional en cambio, hay una idea de inclusión en la negación: se incluye lo indígena como raíz histórica, pero congelado en el pasado, sin coetaneidad ni presente histórico. Avanzo sobre esta idea.

Un primer planteo para analizar la idea de "inclusión en la negación”, se puede encontrar en la obra del ecuatoriano Armando Muyolema-Calle, Colonialismo y representación. Hacia una re-lectura del latinoamericanismo, del indigenismo y de los discursos etnia-clase en los Andes del siglo XX. ${ }^{7}$

En este libro, Muyolema-Calle plantea un recorrido y una aproximación crítica al proceso de emergencia y constitución de Latinoamérica como un proyecto cultural de occidentalización y su articulación ideológica con ciertas líneas del indigenismo y el mestizaje. En ese recorrido aborda, señalando sus diferencias obviamente, a autores esenciales como Vasconcelos, Mariátegui, Retamar, Ángel Rama y Leopoldo Zea, entre otros. Y en ellos, más allá de las diferencias, Muyolema-Calle rastrea una suerte de leitmotiv:

Proyectos intelectuales y sensibilidades políticas, sin duda, dispares, pero, paradójicamente, comparten y se tocan los supuestos de los que parten y sus objetivos políticos y culturales: el genérico "indios" debe ser sacrificado en nombre de la civilización, primero y luego, de la

\footnotetext{
7 Este trabajo fue la tesis defendida por Muyolema-Calle en la Universidad de Pittbusrgh para acceder al grado de Dr. en Filosofía en el año 2007. Muyolema-Calle, A; Colonialismo y representacion. Hacia una re-lectura del latinoamericanismo, indigenismo y de los discursos clase-etnia en los andes del siglo XX; University of Pittsburg; 2007.
}

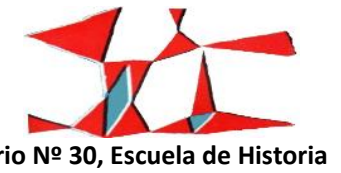

Facultad de Humanidades y Artes (Universidad Nacional de Rosario), 2018

pp. 11-44

ISSN 1853-8835 
Mestizaje colonial y mestizajes estratégicos. Una mirada crítica a la relación entre historia regional e historia indígena

modernización -promesa del porvenir-; proceso y finalidad que encuentran en el mestizaje su viabilidad posible. En su momento germinal América Latina brota a la conciencia como un signo de identidad en constitución, taxativamente excluyente de lo "indio"; el indio no es ignorado sino excluido, por consiguiente, no hay silencios o sustituciones, como en el caso del discurso colonial, sino un discurso profuso y denso que vuelve al indio en objeto que es hablado a través de otro, en objeto de redención mediante un acto sacrificial de destrucción de su cultura, de su proceso civilizatorio. Sacrificio de la cultura y redención del hombre como tabula rasa, como sujeto sin memoria"8

Si pensamos en la intelectualidad argentina de fines del siglo XIX y principios del XX, no encontramos ese "discurso profundo y denso que vuelve al indio en objeto que es hablado por otro" como en Mariátegui, Vasconcelos o Zea, sino un tajante discurso colonial. Esta distinción que señala Muyolema se ajusta a discursos coloniales como el de Sarmiento que dio forma al imaginario de nuestra historiografía nacionalliberal. Pero, si miramos a la historiografía regional ${ }^{9}$ encontraremos exactamente lo que refiere el autor ecuatoriano, un discurso profuso y denso que habla al indio en la lógica de la inclusión-negación.

Veamos cómo funciona esta lógica. Dentro de los proyectos latinoamericanistas del siglo XIX que analiza Muyolema, la pregunta fundamental que históricamente subyace al pensamiento político es ¿Qué hacer con los indios?, y a partir de ella, es que la situación de los colectivos sociales genéricamente denominados "indios" se convierte a principios de siglo XX, en una "cuestión", es decir, en un "problema" a resolver dentro de los proyectos civilizatorios de América Latina ${ }^{10}$. En segundo lugar, al convertir lo indígena en un problema/cuestión, es que aparecen el mestizaje y el indigenismo como las soluciones por excelencia:

Salvando las distancias ideológicas, geográficas e históricas, esta tesis sería suscrita fácilmente por una legión de intelectuales y políticos latinoamericanos contemporáneos y sucedáneos de Jaramillo Alvarado y Vasconcelos. No estamos sin duda, ni de lejos, frente a un argumento descriptivo: lo que

\footnotetext{
8 Muyolema-Calle; 2007; p. 31. Resaltado mío.

${ }^{9}$ Si bien en este artículo solo me detengo en la historiografía de Raúl Armando Bazán, en mi tesis de doctorado, de la cual es parte este trabajo, analizo varios textos historiográficos de la región con el mismo patrón.

10 Muyulema; 2001; pp. 330-331.
}

17

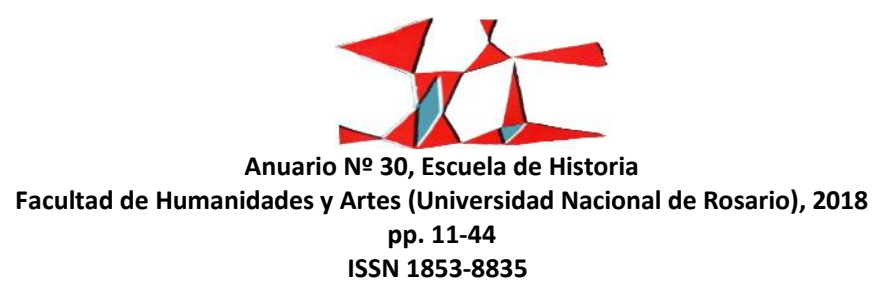


tenemos enfrente es un mensaje profético, un deseo explícito, históricamente compartido, con relación al destino manifiesto de aquéllos que son llamados "indios" ${ }^{11}$.

El mestizaje y el indigenismo ${ }^{12}$ son entonces, los grandes discursos que se construyeron dentro del latinoamericanismo como respuesta a la "cuestión indígena". Por ello, para Muyolema-Calle, no podemos negar que en buena parte de esta intelectualidad "América Latina encarna un proyecto de matriz colonial y ha marcado con sus estrategias simbólicas y políticas los discursos del indigenismo"13 por eso, "el proceso constitutivo de nuestro continente y sus debates fundamentales no pueden ser entendidos sin el reconocimiento de su carácter colonial: su modernidad tiene una dimensión histórica colonial”14 $\mathrm{Y}$ esta dimensión colonial atraviesa de cabo a rabo el mestizaje pero no solo bajo la rúbrica del discurso ideológico del blanqueamiento, sino también a través de un giro político hacia el sujeto mestizo. Esta distinción, el señalamiento de este giro, es lo que quiero recuperar para el análisis de la historiografía regional y de cómo se plasma el mestizaje colonial en ella. Así lo plantea el intelectual ecuatoriano:

Es pertinente señalar que el debate intelectual de/en América Latina estuvo marcado por el fervor del mestizaje. El mestizaje se erigió como una ideología que prometía al destino de Abya-yala/América la utopía del "hombre libre". Las vertientes mayores del pensamiento latinoamericano no solamente reflexionaron sobre la naturaleza de la cultura en esta región, sino que su lectura permitió, simultáneamente, operar un giro hacia lo político: del mestizaje como proceso cultural se pasa al mestizo como sujeto político. Lo mestizo designa una categoría social. Pensar Abya-Yala/América no sólo fue un esfuerzo por comprender su realidad; a mi entender fue también el modo como se produjo a sí mismo este sujeto mestizo es, obviamente, como distanciamiento y como negación de lo "indígena" 15

\footnotetext{
11 Muyulema; 2001; p. 331Por ejemplo: Asimilación a la nacionalidad peruana del indio como proponía Mariátegui, o la reivindicación de un pueblo mestizo como explícitamente sugiere Retamar.

12 En el texto de 2007, Muyolema analiza detenidamente el fenómeno del indigenismo, que aquí dejo de lado. "Es ampliamente aceptado que el indigenismo es un movimiento o una corriente fundamentalmente artístico-literaria y política de reivindicación de/lo indígena con una larga tradición, que se constituye al calor de los debates sobre la "cuestión indígena". Es difícil participar críticamente en el debate sobre el indigenismo sin que por lo menos mencionemos que dentro de esta tendencia existen visiones no solamente diferentes sino muchas veces contrapuestas y antagónicas en relación a los pueblos llamados indígenas y sus procesos culturales Muyulema; 2001; p. 334.
}

13 Muyolema-Calle; 2007; p. 33.

14 Muyolema-Calle; 2007; p. 39.

${ }^{15}$ Muyolema-Calle; 2007; p. 39-40.Resaltado mío.

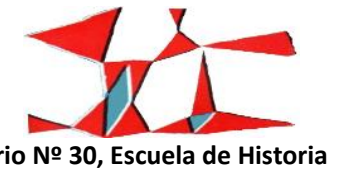

Facultad de Humanidades y Artes (Universidad Nacional de Rosario), 2018

pp. 11-44

ISSN 1853-8835 


\section{Mestizaje colonial y mestizajes estratégicos. Una mirada crítica a la relación entre historia regional e historia indígena}

En este giro hacia lo político, la noción de mestizo, al constituirse en una forma de autopercepción y autonomización como sujeto social se desplaza del ámbito puramente cultural, deja de ser "solo una categoría epistemológica de análisis cultural para encarnar un cuerpo y una voz que pugna, en su emergencia misma, por la hegemonía cultural, en un contexto fuertemente condicionado por la presencia de pueblos que, sin negar el mestizaje como fenómeno y proceso cultural, no se autodenominan ni se reconocen como mestizos. ${ }^{16}$.

De ninguna manera este giro reivindica o reposiciona la idea de mestizaje. Lo definitorio del mestizo sigue siendo su parte europea y no su herencia "indígena", pero en una posición contradictoria donde se reivindica lo mestizo al tiempo que no se autoreconoce. En este particular sentido, lo mestizo, "como categoría social, como asunción de una conciencia de identidad que posiciona política y culturalmente a un sujeto en una escala superior a lo indígena"17 muestra para Muyolema-Calle, justamente cómo operan las estrategias coloniales de control del imaginario de los dominados. Lo mestizo es un lugar político y como tal, "configura no solo un locus de enunciación sino un sujeto de enunciación y de agenciamiento político y

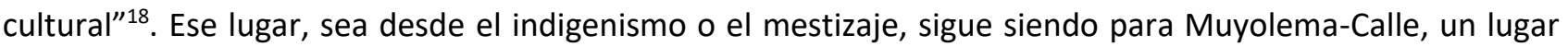
donde la herencia cultural indígena es reprimida, "La lengua, la vestimenta y las costumbres son las que tienen que ser ocultadas como condición del "cruce" y de una precipitación del cambio"19

Lo fundamental, sigue siendo, que en cualquiera de las dos posiciones, o en cualquiera de las dos formas del mestizaje (como discurso ideológico o como asunción de un sujeto político) lo que se impone es una forma de negación de lo indígena. Para el autor, en estos dos registros:

el mestizaje se muestra a sí mismo no solo como un olvido de lo "indígena”, sino como su negación. Como proceso cultural, condicionado por históricas relaciones de poder, el mestizaje significa el olvido

\footnotetext{
16 Muyolema-Calle; 2007; p. 40. Resaltado mío. Una impresión que he recogido a partir de mi trabajo docente en el interior de Catamarca, es que los habitantes de lugares como Belén o Santa María, donde hubo (y hay) una fuerte presencia indígena, no se reconocen ni como mestizos, tampoco como españoles, tampoco como inmigrantes y mucho menos como indios. Aparecen otras figuras como "lugareño" o "local" donde se mezclan algunas identificaciones con el pasado indígena de los calchaquíes, y otras, con una suerte de mestizaje posterior. En este contexto, ¿alguien se animaría a hablar de un sujeto político mestizo en estos contextos? Claramente no, pero insisto, ¿̇entre la formación de los pueblos del interior, de los ciudadanos argentinos del NOA y la indigenización actual, que identidad política histórica podemos señalar? ¿Las montoneras federales de Felipe Varela, quienes las integraban? ¿Dónde podemos enunciar a los indios? ¿Quiénes (en términos históricos) eran ayer, los indios de hoy?

17 Muyolema-Calle; 2007; p. 41.

18 Muyolema-Calle; 2007; p. 48.

${ }^{19}$ Muyolema-Calle; 2007; p. 48.
}

19

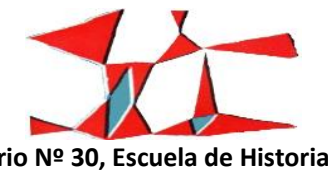

Facultad de Humanidades y Artes (Universidad Nacional de Rosario), 2018

pp. 11-44

ISSN 1853-8835 
de la herencia indígena y, como asunción política, como conciencia de sí y para sí, significa la negación de lo indígena. Olvido y negación parecerían ser dos momentos consecutivos de una operación de desplazamiento y asunción sustitutiva de una nueva inscripción política y cultural. ${ }^{20}$

Llegado este punto, falta la pregunta más importante de todas, ¿quién es este sujeto mestizo que encarna la lógica de la negación y el olvido? ¿Qué ocurre entre la aceptación del discurso del mestizaje y la negación a la autoidentificación como sujetos mestizos? ¿Quiénes son estos sujetos que se posicionan política y culturalmente en una escala superior a la de los indígenas? ${ }^{21}$ Responde Muyolema:

hay que entenderlo como aquel que asimilado o seducido por la cultura occidental ocupa, sin embargo, un lugar problemático en la estructura social al no ser reconocido por los blancos ni por los llamados indios ${ }^{22}$

Esta es la historia de las identidades del NOA, y es también, la posición de historiadores como Armando Raúl Bazán, no reconocidos por los blancos (porteños-burgueses-liberales), ni por los indios (los pobladores locales, campesinos, habitantes de las montañas, quebradas y pueblos del interior, en una palabra, los indios negados). El criollo del NOA a diferencia del criollo porteño o citadino, ocupa un lugar problemático en la estructura social, y en su búsqueda por encajar, asumen un mestizaje que reproduce "la falacia de la múltiple herencia cultural” ${ }^{23}$. Esta misma lógica, es la que se reproduce en la historia regional: se reconoce la herencia indígena, pero se la sacrifican al interior de la historia de la nacionalidad. Me detengo, ahora sí, en la obra de Bazán para mostrar esta operación propia de la colonialidad.

Historia del Noroeste Argentino, cuanta con dieciocho capítulos que recorren desde el afianzamiento de la conquista española en el Tucumán, hasta la sanción de la Constitución Nacional de 1853. De esos dieciocho capítulos, la novedad, son los dos primeros que incluyen como parte de la historia

\footnotetext{
20 Muyulema; 2001; p. 343.

${ }^{21}$ ¿Cómo se vio afectado el imaginario histórico-racial argentino en el proceso que comprende desde la "desaparición" de los diaguitas en el Siglo XVII, hasta su reemergencia como "Unión de Pueblos de la Nación Diaguita" hoy? ¿Cuáles fueron y son las condiciones de posibilidad de ciertas emergencias indígenas? ¿Qué identidades históricas hicieron de soporte y resorte de estas emergencias? ¿Cómo es posible que los indígenas hayan "desaparecido" ya a finales del siglo XVII si actualmente distintas comunidades y sujetos se reivindican como tales? ¿Cómo se expresaron estas paradojas en nuestros imaginarios históricos-raciales? 22 Muyolema-Calle; 2007; p. 40.

${ }^{23}$ Aunque se haya afirmado que -básicamente- el mestizaje resulta del cruce de las culturas europea occidental y la "indígena", resulta claro, sin embargo, que lo definitorio de lo mestizo no es, precisamente, su parte "indígena": como deseo y como actitud celebratoria es notorio una afinidad afectiva y una apuesta por la asunción expresa de una identidad política que se diga mestiza Muyolema-Calle; 2007.
}

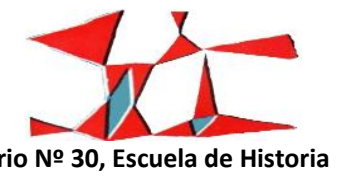

Facultad de Humanidades y Artes (Universidad Nacional de Rosario), 2018

pp. 11-44

ISSN 1853-8835 


\section{Mestizaje colonial y mestizajes estratégicos. Una mirada crítica a la relación entre historia regional e historia indígena}

de la región, el periodo de los siglos XVI-XVII, y especialmente, las Guerras Calchaquíes ${ }^{24}$. Los otros dieciséis capítulos corresponden al periodo que abarca únicamente el siglo XIX, desde los momentos previos a la Revolución de Mayo hasta la conformación de la Constitución Nacional de 1853.

Por la organización de los capítulos ya podemos intuir por dónde irá el derrotero del pasado indígena, finalizadas las Guerras Calchaquíes y afianzada la colonización, los indios irán desapareciendo vía extinción o mestizaje. Pero el gesto inicial de esta y otras historias de la región, es el reconocimiento de la importancia del pasado indígena. Bazán afirma de nuestra región que "durante el tiempo indígena fue la región más poblada y de mayor nivel cultural que hubo en el actual territorio argentino"25, y a su vez menciona la importancia y el desarrollo de la Cultura de la Aguada. No obstante, el peso de este reconocimiento del pasado indígena como parte la historia regional, será rápidamente eclipsado. Me detengo en dos significativos apartados de estos capítulos iniciales donde Bazán aborda el pasado indígena del Tucumán Colonial. El primero se titula, "Estructura étnica y mestizaje”, y los párrafos iniciales resumen a todas luces el sentido ideológico del texto:

Cuando los españoles emprendieron la conquista del Tucumán el primer dato que se nos imponen es la tremenda desigualdad numérica entre la población indígena y los reducidos contingentes de blancos que llegaban para someterla. Ese desequilibrio demográfico y étnico creaba un serio problema para producir una efectiva colonización, esto es para formar una nueva sociedad incorporada a la cultura europea. La conquista de los pueblos autóctonos pudo producirse merced a la superior organización militar y al armamento más moderno: mosquetes y arcabuces contra flechas y piedras. En verdad, el desafío más serio era la colonización, pues de no resolverse este problema la minoría invasora hubiese tenido que vivir velando armas contra una mayoría hostil. Un factor sin duda poderoso para llamar a los indios a la obediencia y predisponerlos a colaborar con los

\footnotetext{
24 Las Guerras Calchaquíes abarcaron los años 1562-1665. Articulando resistencia y rebelión, fue la lucha más sostenida, ardua y planificada, posiblemente de todo el territorio del Tawantinsuyu y de las sociedades libres pre-incaicas y pre-hispánicas. Calchaquí es la denominación histórica recibida por un grupo de parcialidades de la etnia diaguita o pazioca que habitaban las actuales provincias de Salta, Catamarca y Tucumán en el noroeste de la Argentina al momento de la llegada de los conquistadores españoles. Estaban dentro de este conjunto de culturas diaguitas, los yocaviles, quilmes, tafís, chicoanas, tilcaras y purmamarcas entre otros. La denominación "calchaquí" parece derivar de uno de los principales jefes diaguitas que se opusieron a los españoles: Kalchakí llamado por los españoles Juan Calchaquí quien respondía como líder supraétnico en el valle de Yocavil. Véase: Lorandi, A. M; "Las rebeliones indígenas"; en Nueva Historia Argentina; Tomo II; (coord.) Enrique Tandeter; Sudamericana; Buenos Aires; 2000.
}

${ }^{25}$ Bazán; 1995; p. 16.

21

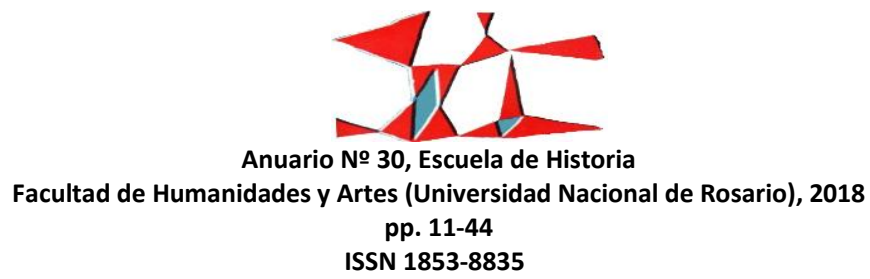


conquistadores fue la iglesia con su labor de evangelización. Salvo casos límites, como la indómita rebeldía de las tribus Calchaquí y del Chaco, bien puede decirse que la cruz de los misioneros fue instrumento más eficaz de colonización que la espada de los guerreros ${ }^{26}$. El otro instrumento fue el mestizaje ${ }^{27}$

Lo primero que llama la atención es el señalamiento de una "efectiva" colonización, que marca la diferencia entre conquista y colonización. Es decir, que más allá de la ocupación territorial (conquista), la colonización debía avanzar en la dirección cultural para formar una nueva sociedad "incorporada" a la cultura europea. La contradicción, o si se quiere, los límites epistémicos de la narración histórica que organiza Bazán, le permiten recuperar esta importante época histórica del pasado indígena, pero el marco explicativo es la comprensión del mestizaje que se define bajo la idea de una mezcla donde lo indio se incorpora a lo blanco-criollo, para desaparecer en la nueva cultura. Como señalábamos anteriormente, no se trata de una negación absoluta de lo indígena, sino de una inclusión en la negación, una inclusión contenida en los límites temporales del siglo XVII que se funde y difumina en una nueva identidad. Este tipo de mestizaje tiene una dimensión histórica que pone de relieve el carácter epistémico-colonial de su lógica, un mestizaje que:

Se reactualiza para señalar la imposibilidad de la racionalidad histórica de corte occidental para reconocer simultaneidades espacio-temporales. Aquello que Johannes Fabian conceptualizó "como dilación temporal" identificado como una negación de coetaneidad, y nos sirve para caracterizar la lógica del orden histórico con relación a la presencia de lo indio en el horizonte cultural de las naciones(...)La metáfora del indio como raíz histórica opera también como negación de la coetaneidad de los pueblos indígenas: toda proposición política de los llamados indios es descalificada por los no indios porque, según ellos, tales proposiciones, encarnan "utópicas arcaicas" y presentaciones de "retorno al pasado"28

\footnotetext{
${ }^{26}$ Una segunda cuestión, importante es el papel evangelizador de la iglesia como el instrumento más efectivo de la colonización cultural Todo el texto de Bazán está repleto de referencias al trabajo pacífico de evangelización de la Iglesia, incluso llegando en ciertos casos hasta halagos para algunos de sus personajes. Casi en ningún momento hay una problematización de las responsabilidades que le cupo a la Iglesia en el genocidio de la conquista.

27 Bazán; 1995; pp. 32-33. Resaltado mío.

28 Muyulema; 2001; p. 354.
}

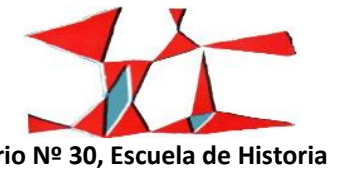

Facultad de Humanidades y Artes (Universidad Nacional de Rosario), 2018 
Mestizaje colonial y mestizajes estratégicos. Una mirada crítica a la relación entre historia regional e historia indígena

En el eje del texto de Bazán está la imposibilidad de reconocer simultaneidades espacio-temporales, es decir, se puede reconocer la herencia indígena solo como raíz histórica y no como elemento del presente histórico, una vez más, inclusión en la negación. Este carácter de la historia regional se distancia de la historiografía nacional burguesa liberal, donde la negación del pasado indígena es total. Existe una diferencia muy grande entre lo que fue el nacionalismo argentino, de los nacionalismos del resto de Latinoamérica. Uno podría decir que México y Argentina, señalan exactamente los límites radicalmente opuestos de dos formas de tratamiento del pasado indígena, el primero haciendo un paroxismo de la inclusión en la negación, toda la identidad mexicana se construye mirando el pasado Azteca, y del otro extremo, la idea argentina de una descendencia pura y exclusiva de los europeos y una negación radical de los elementos indios y negros. En el medio podríamos ubicar las variantes particulares de Bolivia, Perú, Venezuela, Ecuador, Brasil, etc.

Volviendo al texto de Bazán, del mestizaje en concreto se dice poco, que la mayoría de los colonos "tuvo descendencia con las mujeres del país y así comenzó el proceso del mestizaje que dio nacimiento a una nueva sociedad"29 y refiriéndose al exterminio del indio, tanto por el trabajo excesivo como por la guerra: "por uno y otro motivo, los indios para repartir se fueron acabando y las encomiendas se tornaron menos lucrativas. Y como el sistema económico se basaba en el trabajo del indio fue necesario introducir negros que llegaban por el Río de la Plata" ${ }^{30}$. Al final de este primer capítulo la situación que se describe para el Tucumán Colonial en la segunda mitad del siglo XVII, es la siguiente:

Los pueblos indios fueron disminuyendo en número y en habitantes: en la paz, porque fue inveterado el abuso de los encomenderos de sacar a los aborígenes de sus tierras para hacerlos trabajar en sus estancias; en la guerra, porque la profunda conmoción que significó las guerras calchaquíes produjo la extinción o el extrañamiento de muchos pueblos. ${ }^{31}$

Y finalmente se nos da un resumen del cuadro étnico, posterior al padrón de 1778

29 Bazán; 1995; p. 34.

30 Bazán; 1995; p. 34.

31 Bazán; 1995; p. 35.

23

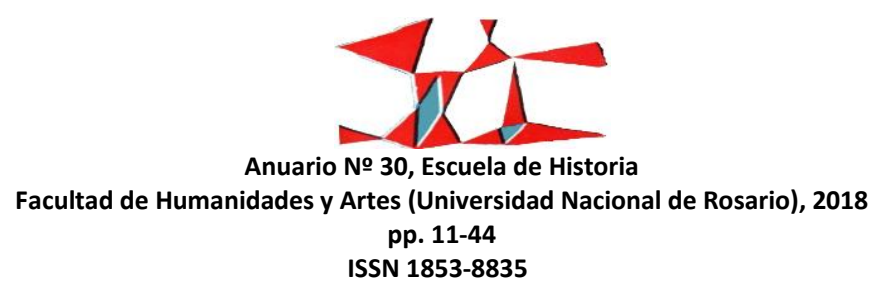


El cuadro étnico es ahora más complejo y diverso. Hay españoles europeos y criollos, indios y mestizos, negros, mulatos y zambos. El dato relevante es la irrupción masiva del negro y de sus formas mestizas que se constituye en el grupo racial mayoritario: 39.800 individuos, el $45 \%$ de la población de las seis ciudades (...) seguía en importancia la población indígena con 31.234 individuos ${ }^{32}$

En el tránsito de dos páginas Bazán conjuga una serie de afirmaciones imposibles. Que los "negros y sus formas mestizas" son mayoría poblacional, que los indios son la segunda mayoría poblacional y al mismo tiempo se extinguen, que una nueva sociedad criolla se forma, que esa sociedad representa un cuadro étnico muy complejo, pero que el mismo debe reducirse a "incorporarse" a la cultura europea. Necesitaríamos de mayor espacio para detenernos en cada párrafo de la obra de Bazán donde encontramos las pruebas de cómo funciona esta lógica. Pero con lo brevemente analizado aquí, podemos afirmar que en Historia del Noroeste Argentino, nos encontramos que no hay un olvido de lo indígena, pero sí su negación, aparece la idea de lo indígena como una raíz histórica profunda, importante en la formación de la "matriz étnica" de la nacionalidad, pero a su vez, como una raíz que desaparece en el mestizaje de la identidad criolla; y encontramos, en la asunción político-ideológica del autor, un mestizaje falaz que reafirma la negación de la indígena y, finalmente, una racionalidad histórica anclada en la negación de coetaneidad de las sociedades indígenas desde el siglo. XVIII en adelante. Finalmente, traigo una contundente afirmación de Bazán, realizada en su artículo "El Método de la historia Regional", donde aparece con cierta irrisoria sinceridad esta lógica sobre el pasado indígena. Afirma Bazán en primer lugar:

"La homogeneidad de una región histórica depende también del tipo étnico que protagoniza su desarrollo. En el Noroeste ha sido y sigue siendo mayoritario el tipo humano producido por el primer mestizaje. El criollo se plasmó en su ser físico su idiosincrasia como producto del mestizaje del colonizador español -reducida minoría- con el aborigen americano, estrato originariamente mayoritario, y con los grupos africanos incorporados masivamente a partir del siglo XVIII. Esos elementos formaron la sociedad criolla que decantó su perfil en el siglo XIX, borrando los rasgos identificatorios particulares de sus componentes primarios. $^{33}$

\footnotetext{
32 Bazán; 1995; p. 37.

${ }^{33}$ Bazán; (p. 4) Fuente: http://www.fundacioncultural.org/revista/nota7 40.html

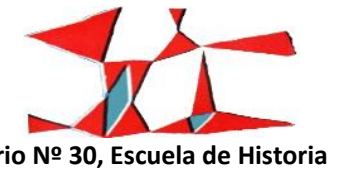




\section{Mestizaje colonial y mestizajes estratégicos. Una mirada crítica a la relación entre historia regional e} historia indígena

"Componentes primarios" es el eufemismo utilizado para referirse a las culturas indias y negras. Lo que se borra, claramente, es la herencia indígena en el proceso de mestizaje. $\mathrm{Y}$ apenas unas líneas más adelante afirma:

...respecto del tipo étnico de la región pampeana. Esta cambió su población con la incorporación masiva del inmigrante europeo desde la segunda mitad del siglo pasado, donde fueron mayoría los contingentes italianos y españoles. De ello resultó una sociedad aluvial cuyos rasgos físicos y comportamientos culturales modificaron profundamente la fisonomía de la sociedad criolla receptora. Esta es la Argentina gringa cuya idiosincrasia no responde al modelo de "crisol de razas" como se creyó durante muchos años sino más propiamente a un pluralismo étnico y cultural. Y esto influye en todas las manifestaciones sociales, incluso en la forma de sentir el país y de conceptualizar sus relaciones con América y el mundo.

Bazán reconoce perfectamente el intento de homogeneización que impuso la "Argentina gringa" y denuncia el modelo del crisol de razas, por un "pluralismo étnico y cultural". No obstante, su pluralismo étnico y cultural desconoce, borra, vuelve a sobreponer una lógica colonial al pasado indígena, su pluralismo étnico y cultural, es por el contrario, un mestizaje colonial, bajo la lógica de la inclusión en la negación. Este es el paso que Muyolema señala como el giro hacia el sujeto político, que

Conceptualmente produce una mirada y construye un objeto; es un producto intelectual que disciplina la mirada, contribuye a construir formas de ver la realidad y establece lugares y jerarquías sociales. (...) la mirada pretendidamente objetiva del intelectual compromete inexorablemente su subjetividad en el manifiesto y celebratorio deseo del mestizaje"34

Este es el fenómeno que atraviesan las posturas de Armando Raúl Bazán y de otros intelectuales que han sido fundamentales para el pensamiento de la región, como la destacada figura de Adán Quiroga ${ }^{35}$. Y

\footnotetext{
${ }^{34}$ Muyolema-Calle; 2007; p. 45. 25

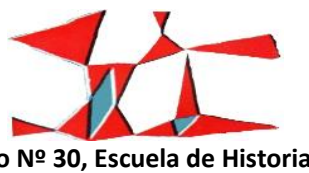

Facultad de Humanidades y Artes (Universidad Nacional de Rosario), 2018

pp. 11-44

ISSN 1853-8835
}

${ }^{35}$ Adán Quiroga (1863-1904) se encuentra en la sin dudas en la lista de los grandes pensadores de nuestro país. En su corta vida fue político, jurista, poeta, arquéologo, historiador, periodista y estudioso del folclore argentino. En su obra cuentan importantes e influyentes textos para la región del NOA como La Cruz de América, Folclore Calchaquí y Las guerras calchaquíes. A pesar de su importancia, es interesante mencionar que hoy en día se han realizado algunas (marginales) lecturas que matizan la figura de estos 
esta intelectualidad, remata el pensador ecuatoriano, "que asumió el mestizaje como sujeto político colaboró en el proceso de negación y exclusión de la herencia indígena, tal como se podía apreciar en la constitución ideológica de sus discursos". ${ }^{36}$ Por todo lo señalado hasta aquí, la historia regional de Bazán (y una gran cantidad de obras escritas bajo su misma impronta) podrá ser una historia contra la homogeneización del nacionalismo, contra el centralismo histórico-porteño y la invisibilización de las provincias, pero de ninguna manera, podrá ser una historia del pasado indígena. Una historia que abra puertas al pasado y a la herencia indígena, que nos permita pensar los procesos históricos, políticos e identitarios de los pueblos Diaguitas, Calchaquíes, Collas, Aconquijas, Atacameños, y tantos otros, sin cuyo pasado la historia de la región, seguirá siendo una historia colonial.

\section{Multietnicidad y ambivalencia. Mestizajes estratégicos en las identidades del NOA.}

He afirmado al inicio de este artículo que el imaginario racial del mestizaje expresado en la "Historia oficial" de los siglos XIX y XX de nuestro Estado-nación argentino, ha sido fundamental en la visión simplista y reduccionista que se construyó sobre los procesos de transformaciones vividos por las sociedades indígenas. ¿Cómo recuperar esos procesos para la historia contemporánea? ¿Cómo se relacionan los sucesos del pasado indígena con la historia nacional argentina? ¿Qué narraciones habilitan a pensar el pasado indígena en la historia regional?

Mi pregunta por la posibilidad de los mestizajes estratégicos se ubica en el tránsito de dos situaciones históricas que vinculan la historia colonial, la historia regional y el presente histórico, se ubica, para decirlo con más precisión en las siguientes preguntas: ¿Cómo se vio afectado el imaginario racial argentino/provincial, en el proceso que recorre desde la "desaparición" de los diaguitas en el siglo XVII, hasta su reemergencia como "Unión de Pueblos de la Nación Diaguita37” hoy? Esta pregunta específica se

autores, por ejemplo, tensionando los modos en que ejercieron su labor arqueológica y lo que hoy se considera la expropiación de restos materiales y espirituales de las comunidades. En otros trabajos he analizado sus obras mostrando también características coloniales en su concepción historiográfica en relación a la historia indígena de nuestra región NOA.

${ }^{36}$ En todas las historiografías regionales y provinciales del noroeste, efectivamente el mestizaje termino por convertirse en un sujeto etéreo, sin corporeidad social, y que termino siendo una ideología de transición hacia la cultura imperial del "abuelo paterno" (Italiano, español, alemán, etc.) y una negación estigmatizante de la "herencia materna" indígena (en el caso de la herencia Colla es muy notorio este sentido).

37 “La existencia del pueblo Diaguita data de más de 9.000 años y su ámbito territorial comprendió antiguamente una extensión que integraba el sur de Salta, el oeste de Tucumán, Catamarca, La Rioja, Santiago del Estero y el otro lado de la Cordillera de Los Andes. (...) Las Comunidades Indígenas descendientes de aquellos pueblos somos quienes en el presente llevamos desde la década de 1970 un proceso de reorganización, toma de conciencia con la realización en diciembre de 1973 del Primer Parlamento Indígena "Juan

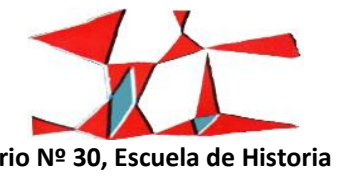

Facultad de Humanidades y Artes (Universidad Nacional de Rosario), 2018

pp. 11-44

ISSN 1853-8835 


\section{Mestizaje colonial y mestizajes estratégicos. Una mirada crítica a la relación entre historia regional e historia indígena}

relaciona también con algunos interrogantes más generales que hacen a la problemática de la historiografía indígena, como ser: ¿Cuáles fueron y son las condiciones de posibilidad de ciertas emergencias indígenas? ¿Qué identidades históricas hicieron de soporte y resorte de estas emergencias? ¿Cómo es posible que los indígenas hayan "desaparecido" ya a finales del siglo XVII si actualmente distintas comunidades y sujetos se reivindican como tales? ¿Cómo se expresaron estas paradojas en nuestros imaginarios históricos-raciales? ${ }^{38}$

Para recorrer estos interrogantes, contamos desde la década de 1990 con una serie de investigaciones que se mueven entre la etnohistoria y la antropología cultural, que nos permiten realizar otras miradas y análisis sobre la historia del noroeste argentino, y sobre las cuales me apoyaré para intentar responder los interrogantes propuestos. Es a partir del análisis de esos trabajos que propongo la categoría de mestizajes estratégicos, con la cual, pretendo desarrollar la idea de unos mestizajes no exclusivamente de homogeneización y blanqueamiento, sino como procesos más complejos y ambiguos, remarcando siempre, que no se trata de negar la ideología del mestizaje, sino preguntarse por ciertas ambivalencias en las cuales los mestizajes se convirtieron y convierten en estrategias de resistencia y persistencia ${ }^{39}$.

En las líneas que sigue, bosquejaré esta idea de mestizajes estratégicos, como categoría analítica que puede ayudarnos a pensar ciertos imaginarios raciales de difícil aprehensión en relación a la historia indígena. La posibilidad de rastrear estos mestizajes estratégicos, apunta a su vez, a cotejar la existencia de cierto sesgo colonial (criollo - porteño céntrico) que no puede ver en el mestizaje más que un proceso de invisibilización, apropiación, aculturación y negación; es decir, una mirada focalizada solamente en aspectos y consecuencias negativas del mestizaje como discurso de una ideología nacional-criolla y como dato "biológico" de "extinción" del componente étnico indígena de la sociedad colonial devenida nacional.

Calchaquí" en Amaicha del Valle. Desde entonces algunas comunidades empezaron a participar del proceso de lucha por el reconocimiento de los derechos de nuestros Pueblos a pesar de épocas de mucho estancamiento y persecución como la del último proceso militar. Posteriormente a partir del año 2000 se empezaron a reunir las diversas comunidades, tanto de la provincia de Tucumán como algunas de Catamarca y Salta. Este proceso dio como resultado la constitución de la Unión de Pueblos de la Nación Diaguita, (UPND), el día 3 de julio de 2005, en Quilmes, Tucumán" Documento Presentado el 3 de setiembre de 2012. Al Sr. Presidente de la COMISION BICAMERAL DEL H. CONGRESO DE LA REPUBLICA ARGENTINA. Disponible en: http://upndsalta.blogspot.com/

38 Este tipo de interrogantes son los que se realiza, por ejemplo, Lorena Rodríguez en su interesante libro Después de las desnaturalizaciones. Transformaciones socio-económicas y étnicas al sur del valle Calchaquí. Santa María, fines del siglo XVII - fines del XVIII; Buenos Aires; Antropofagia; 2008.

39 Uso la idea de persistencia para señalar una resistencia de larga duración. Resistencia silenciosa, soterrada, episódica. Volveré más adelante para precisar esta idea.

27

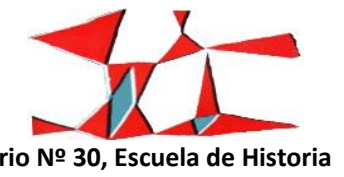

Facultad de Humanidades y Artes (Universidad Nacional de Rosario), 2018

pp. 11-44

ISSN 1853-8835 
Si bien iré precisando la definición de mestizajes estratégicos, podemos dar cuenta de ella inicialmente de la siguiente manera. Entiendo el mestizaje estratégico como un lugar de enunciación inestable, que permite rastrear y comprender la articulación de identidades históricas de difícil aprehensión como son, por ejemplo, las de poblador, local, lugareño, y sus relaciones con identificaciones indígenas, como ser las de "antepasados", "ancestros", "curandero", "comuneros", “caciques", etc. El concepto de lugar de enunciación inestable,

remite a un referente lábil que, como tal, se constituye conformando un lugar de enunciación ontológicamente inestable, en el que coexisten al menos dos universos de sentido sin reducirse el uno al otro, y como epifenómeno de la expansión de occidente sobre América, forma parte de lo que Mignolo denomina "semiosis colonial" 40

Bajo esta definición, señala Silvia Tieffenberg, "la idea de "mestizo" se desplaza, desde una perspectiva biocéntrica hacia una perspectiva situacional que inscribe al sujeto/cuerpo en el locus enunciativo que lo gesta. Abordar la idea de "mestizo" desde su lugar de enunciación permite reponer el contexto social, político y cultural implicado, y aprehenderla, no como un hecho del pasado sino como un proceso inacabado, que comienza con la llegada de españoles y portugueses a América, y que al presente muestra una notable actividad. ${ }^{41}$

En esta línea, propongo la idea mestizajes estratégicos, como lugares de enunciación ontológicos inestables, con dos objetivos. En primer lugar, como categoría crítica capaz de dar cuenta de ciertas contraposiciones "dicotómicas y transparentes" que se presentan en la historia para explicar las transformaciones entre pasado y presente indígena. $Y$ en segundo lugar, para combatir cierto esencialismo historiográfico que define todas las categorías sociales y representaciones identitarias como fijas: la de español, la de criollo, la de mestizo y la de indio. Contra ese esencialismo, propongo reconstruir otras formas de continuidad en las identidades colectivas indígenas, que tensionan los límites de lo que nos permite pensar nuestro imaginario histórico- racial.

Utilizaré para poner en discusión la categoría propuesta, dos estudios. El primero, de Ana María

\footnotetext{
40 Tieffenberg; 2013; p. 277. Resaltado mío.

41 Tieffenberg; 2013.
} 
Mestizaje colonial y mestizajes estratégicos. Una mirada crítica a la relación entre historia regional e historia indígena

Lorandi, constituye un conjunto de reflexiones realizado luego de varios años de trabajo de campo en el Noroeste Argentino, y específicamente, en la localidad de Santa María, prov. de Catamarca en la región de los Valles Calchaquíes ${ }^{42}$. Y en segundo lugar, una sugerente y potente obra como es Indios Muertos, Negros Invisibles. Hgemonía, Identidad y Añoranza (2008) de Jose Luis Grosso.

Empiezo por el texto, "El mestizaje interétnico en el noroeste argentino. Problemas y métodos" (1992) de la gran etnohistoriadora argentina, Ana María Lorandi. Allí, señala que el punto de partida hará foco "en las condiciones estructurales de la sociedad nativa del noroeste argentino y en las transformaciones que se producen desde finales del siglo XV hasta finales del XVIII"43, pero, aclara la autora, con el objetivo de dar cuenta de un proceso histórico que culmina y explica la realidad actual. Por eso, pondremos en diálogo dicho texto con uno de los últimos trabajos de Lorandi en el NOA, del año 2005.

De los muchos problemas planteados en aquel texto fundamental, me interesa retener dos ideas, por un lado, la de relaciones interétnicas y por el otro, la de multietnicidad. En pocas palabras, podríamos decir que uno de los objetivos centrales de la autora es romper con la caracterización simple y esencialista que se realizaba sobre el Tucumán Colonial. Contra ello, lo primero que se propone, es analizar cómo era la región antes de la llegada de los españoles, es decir, cómo es el proceso entre las sociedades indígenas prehispánicas del NOA y las interacciones que surgen a partir de la expansión del Tawantinsuyu sobre estos territorios a fines del siglo XV. Para describir y analizar este proceso se propone una mirada estructural que observe lo conflictos y tensiones en las fricciones interétnicas:

Abandonando el fácil esquema de relaciones basadas en préstamos aculturativos realizados en condiciones de libre elección, [y] se empezaron a incorporar los condicionantes que impone la situación colonial, porque presenta perfiles propios y es ese el espacio donde se construye una nueva unidad social en base a la estructuración de diversos sectores que conservan su diferenciación gracias a la mezcla de coacción política e interdependencia económica asimétrica ${ }^{44}$

A modo de novedad teórica, Lorandi, introduce como eje de la situación colonial, la coacción política

\footnotetext{
42 Los departamentos de Belén y Santa María, ambas en los Valles Calchaquíes, cuentan con la mayor cantidad de comunidades indígenas de la provincia de Catamarca.

43 Lorandi; 1992; p. 133.

44 Lorandi; 1992; p. 134.
}

29

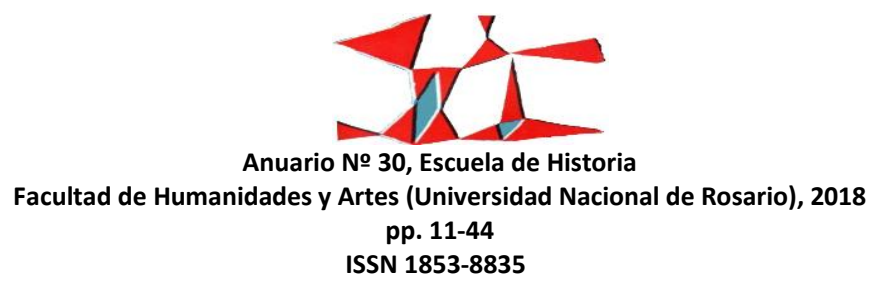


y la interdependencia económica asimétrica, junto a la idea de procesos de diferenciación. En relación al mestizaje este proceso lleva a tener en consideración "el grado de incorporación y mestizaje que soportan las poblaciones nativas y sus consecuencias en la conformación de las identidades regionales en el espacio de colonización iberoamericano" 45 Si en el registro de la historia regional, el mestizaje empieza con la llegada de los españoles, en este planteo, las relaciones interétnicas muestran que el fenómeno tenía condiciones y antecedentes anteriores fundamentales para entender la región. Para Lorandi, "resulta evidente que es necesario focalizar la atención sobre las condiciones estructurales dentro de las cuales se produce el mestizaje porque es uno de los temas centrales para profundizar en la comprensión de la compleja, y crítica, realidad presente ${ }^{46} \mathrm{Al}$ igual que para Muyolema, el mestizaje es uno de los temas centrales para comprender la complejidad del presente de las sociedades indígenas. En el caso de Lorandi, lo primero es la crítica a la simplificación de los enfoques interraciales, que descuidan un complejo proceso al dejar de lado las relaciones interétnicas, "complejidad que se vincula con los intercambios biológicos y culturales entre diferentes etnias americanas, porque las relaciones interétnicas adquieren una infinita gama de modalidades y el mestizaje es una de ellas" 47

En esta línea, para la autora, el proceso de colonización no sólo detuvo los intercambios interétnicos, sino que les otorgó una nueva dimensión, ya sea que se realizaran como parte de las estrategias adaptativas o que fueran producto de la coacción política para reducir el margen de maniobra de las comunidades cuando sus reacciones implicaban un peligro para la estabilidad del sistema colonial. Este análisis lo ubica en particular Lorandi, sobre "el mestizaje interétnico en contextos forzados por presiones que emergen de los Estados dominantes, tomando los ejemplos del Estado inca y el Estado colonial español, y circunscribiendo el análisis al ámbito específico del noroeste argentino"48 Aquí encontramos una primera modalidad del mestizaje estratégico. En los contextos opresivos que mencionamos, el mestizaje adquiere una mayor complejidad. La etnohistoriadora insiste en que, en estas situaciones coloniales, la subordinación a la que todos los grupos están sometidos suele dar lugar a reacciones contradictorias y no necesariamente excluyentes, "Es así que pueden agudizarse y multiplicarse las fricciones interétnicas, puede potenciarse la capacidad de respuesta violenta frente a la presión colonial, o bien anular esa capacidad de respuesta

\footnotetext{
45 Lorandi; 1992; p. 134.

46 Lorandi; 1992; p. 135.

47 Lorandi; 1992; p. 135. Resaltado mío.

48 Lorandi; 1992; p. 136.
} 
Mestizaje colonial y mestizajes estratégicos. Una mirada crítica a la relación entre historia regional e historia indígena

haciendo que la vida cotidiana transcurra dentro de un trasfondo de sorda y opaca resistencia que culmina en anomia social generalizada"49 Esta multiplicidad de respuestas no solo da cuenta de la complejidad de la agencia indígena ${ }^{50}$, proceso que es minuciosamente detallado por Lorandi, junto a la implantación de mitmaquna incaicos en territorio del NOA y al papel fundamental que jugaron en la época de la conquista, (unas veces estableciendo alianzas con las comunidades nativas, y otras, con los españoles), sino que, mucho antes del mestizaje colonial (criollo y blanqueador), hubo otras relaciones interétnicas, otros mestizajes estratégicos, que fueron desplegados como parte de estrategias de resistencia por parte de las poblaciones nativas.

Si a priori pareciera un poco lejana esta búsqueda en los procesos dados en el siglo XV, al objetivo de este escrito, debemos tener en cuenta que, para la comprensión de las Guerras Calchaquíes, como de todos los procesos de resistencia y rebelión indígena durante los siglos XV, XVI y XVII, es fundamental comprender las articulaciones estratégicas que desplegaron los pueblos indígenas, tanto como sus enfrentamientos y disputas, y las alianzas de algunos de ellos con los españoles. Un dato clave en el devenir de la historia colonial, para Lorandi, y que compartimos con ella, es comprender este proceso de implantación de mitmaqunas y su desarrollo, una pieza central del rompecabezas de las posteriores alianzas y luchas, y por supuesto, del cuadro étnico posterior. A modo de ejemplo, podemos señalar el caso de los pulares:

Estos pulares siempre fueron considerados étnicamente diferentes a los originarios aunque desconocemos su filiación; para ser más explícitos, no se los incluye en el tronco diaguita. De allí la importancia que adquiere el hecho de que resulte ser el grupo hegemónico de ese sector desde el siglo XVI, manteniendo una conducta contradictoria frente a los españoles. O sea, alteraron la alianza con la rebelión y conservaron una permanente hostilidad con los ocupantes del resto del valle, en especial con los calchaquíes propiamente dichos, con quienes tenían conflictos de límites ${ }^{51}$.La misma ambigüedad se les atribuye a los de Amaicha instalados a horcajadas entre el valle Calchaquí y el de Tafí, con derechos sobre las pasturas de las altas cumbres. Estos amaichas fueron los únicos que pudieron negociar tierras comunales con las autoridades una vez que acabaron las guerras a fines del

\footnotetext{
49 Lorandi y Boixados 1987-88; p. 136.

50 La cuestión de la agencia es otro de los puntos fundamentales negados en las historiografías regionales que he trabajado con detenimiento en mi tesis de doctorado, de la cual es parte este artículo.

${ }^{51}$ Lorandi y Boixados 1987-88.
}

31

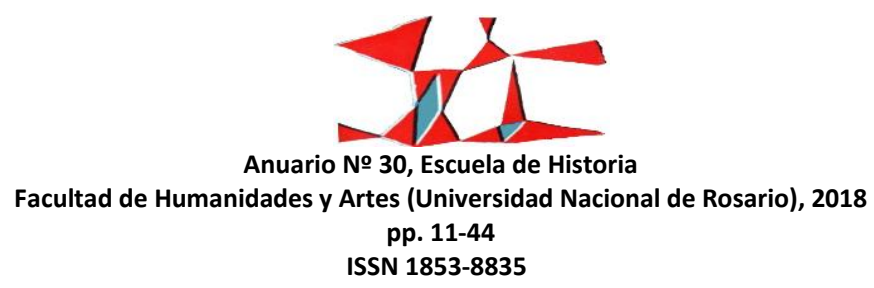


siglo XVII. ${ }^{52}$

Lorandi recorre una variada cantidad de fuentes documentales y analiza en detalle estos momentos de fuerte movilización de mitmaquna, y cómo intervinieron el panorama de las relaciones interétnicas. En el texto se puede recorrer con detalle ese proceso. Me interesa en cambio, las reflexiones que realiza la autora a partir de ese proceso histórico de relaciones interétnicas, que nos conduce a la, segunda idea de mi interés, a saber, la de multietnicidad:

La primera reflexión ronda en torno a la multietnicidad y sus efectos. Cualquiera haya sido la composición étnica y la estructura política de la región en tiempos pre-incaicos, es evidente que las alteraciones demográficas incaicas acrecentaron la fricción interétnica, porque la redistribución de tierras no sólo debió hacerse en base a la ampliación de las áreas cultivables o reasignando las de la población desnaturalizada, sino que para reducir el poder de los antiguos cacicatos, muchos de los mitmaquna adquirieron derechos territoriales y políticos que anteriormente habían pertenecido a los originarios. Las relaciones de poder se resignificaron, sobre todo después de la caída del Cuzco. ${ }^{53}$

Este es el cuadro previo a la llegada de los españoles. Un cuadro que de ninguna manera podría ser resumido a las consabidas ideas de unas sociedades bárbaras y desorganizadas como se instaló en el imaginario popular. Pero también, una idea de multietnicidad que nos señala cierto riesgo en la construcción de la "originariedad" de los pueblos indígenas hoy. Cuando se acusa a ciertos pueblos de "falsos indígenas", pero también cuando desde el Estado se exige el certificado de originalidad, se proyecta una idea de culturas estáticas y fosilizadas en el tiempo, que niega las transformaciones, la coetaneidad y el devenir de los pueblos indígenas. Por lo tanto, esta misma multietnicidad que Lorandi rastrea ya en los siglos XV y XVI, nos señala para nuestro presente un argumento antiesencialista en la impugnación que se hace de la "originariedad" de las comunidades indígenas. Pero así como nunca hubo etnicidad pura, tampoco hubo mestizajes puros, esa es el otro lado de la moneda, de esta multietnicidad.

Como afirma en todo momento Lorandi, es difícil establecer el grado de mestizaje que se produce

52 Cruz; 1990. Lorandi; 1992; p. 142.

53 Lorandi; 1992; p. 144. 


\section{Mestizaje colonial y mestizajes estratégicos. Una mirada crítica a la relación entre historia regional e historia indígena}

entre los antiguos colonos (mitmaqunas) y las poblaciones originales, porque se ignora en qué medida los primeros abandonaron el territorio una vez que se destruye el aparato estatal del Tawantinsuyu. Pero los privilegios otorgados a estos intermediarios del poder central pudieron alentar a muchos de ellos a permanecer en esta región, y bajo ciertas circunstancias, en especial la lucha que los unía frente a un nuevo invasor, superar los viejos conflictos y actuar mancomunadamente en la defensa de sus territorios ${ }^{54}$.

Así pues, antes y durante la llegada de los españoles, nos encontramos con un contexto de multietnicidad y de relaciones interétnicas que se articularon en distintos procesos de lucha y resistencia, a manera, de mestizajes estratégicos.

Ahora bien, ¿̇se puede trazar una línea de análisis entre estos procesos ocurridos en el Siglo XV y XVI y los procesos actuales de re-emergencia indígena? Para desandar esta ardua pregunta, pongo en relación lo desarrollado hasta aquí con el trabajo que realizó el equipo de investigaciones de etnohistoria coordinado por Lorandi en la región de Santa María, provincia de Catamarca; específicamente con dos investigaciones que abarcan el periodo que va desde la década de 1960 hasta la primera década del siglo XXI. El trabajo publicado en el año 2005, "Apropiaciones y usos del pasado. Historia y patrimonio en el Valle Calchaquí", representa un caso que pone de relieve y potencia esta idea de una revisión de los procesos y matices del mestizaje. El artículo, además de recoger reflexiones metodológicas y teóricas, apunta directamente al tema de la identidad en la región: “¿Cómo construyen su identidad los actuales pobladores de Santa María? ¿Existe(n) apropiación(es) de este pasado al momento de construir la identidad? ¿Dicha apropiación es diferencial u homogénea? ¿Qué rol juega la escuela, el museo local y las instituciones políticas al momento de tipificar identidades?"55

\footnotetext{
54 Para no extenderme con los datos que ofrece Lorandi sobre su hipótesis de multietnicidad, valga esta mención: El caso más evidente es lo que se produce desde el centro al sur del valle Calchaquí; en el resto del noroeste la situación es menos clara por el momento. Sin embargo, es probable que parte de los tucumano-santiagueños instalados en las proximidades de las ciudades de Andalgalá o de Londres (en los centros incaicos de Potrero-Chaquiago o Shincal) hayan permanecido en sus nuevos dominios. Lo mismo ocurrió aparentemente con los que ocuparon el valle de Catamarca. La descripción del aspecto de los indios de este valle que nos aporta una relación temprana, así como las posteriores visitas de los misioneros jesuitas, confirman que se trata de gente que vestía y se comportaba a la usanza de los juríes de la frontera oriental, pues usaban ropas hechas de plumas e impresionaban como menos "socializados" que los diaguitas del oeste de la provincia. Entremezclados con ellos encontramos mitmaquna del Collao, como lo sugiere la presencia de un pueblo llamado Collagasta, siendo también gasta que alude a "pueblo de los collas" Lorandi; 1992; p. 145.

55 Rodríguez \& Lorandi; 2005; p. 433.
}

33

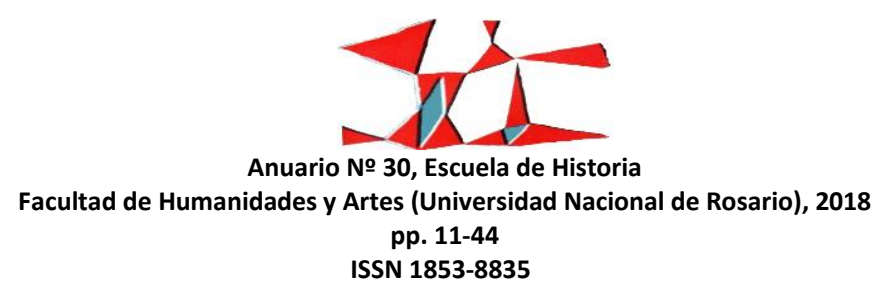


Para responder estas preguntas, Lorandi y Rodríguez contrastan las impresiones y reflexiones de su primera instancia en Santa María en la década del 60 con las últimas en el año 2005. Y si bien señalan que su objetivo central nunca fue un estudio sobre la identidad de los santamarianos, también mencionan lo inevitable que fue realizarse estas preguntas a medida que fueron pasando los años de trabajo en la localidad. Las investigaciones antropológicas que realizó el equipo en aquella época "se focalizaron principalmente en problemas del campesinado, más que en identificaciones étnicas y sus relaciones con la memoria histórica", no obstante, señalan las autoras,

...a partir de nuestros contactos con la población rural, mediada por los peones que colaboraban en las excavaciones arqueológicas y con quienes solíamos sostener largas e informales charlas, así como con la clase media urbana de la ciudad de Santa María con la que mantuvimos una estrecha relación social. Es obvio que las investigaciones de los arqueólogos, cuyas experiencias estamos compartiendo con nuestros lectores, no tenían por objetivo profundizar el tema de la identidad. Pero, para nosotros, originarios del litoral "gringo» de la Argentina, los pobladores de estos valles eran culturalmente diferentes, y la otredad de los santamarianos despertaba nuestra curiosidad, además de ser un asunto central desde la perspectiva antropológica. ${ }^{56}$

En esta primera aproximación a esa curiosidad en crecimiento, las autoras se encuentran que el primer nivel de identificación de los santamarianos era la adscripción a la provincia de Catamarca. El ser catamarqueño era una forma constante de autoidentificación, con fuerte carga de orgullo y hasta de desafío hacia algunas de las regiones colindantes. La oposición más notable se establecía con los tucumanos, sus vecinos más inmediatos, considerados ladrones y poco sinceros. Respecto al pasado indígena

Si bien no podían ignorar y no ignoraban la existencia de abundantísimas ruinas arqueológicas (demostración de una notable densidad demográfica prehispánica) que habían sido el asiento de los indígenas (...) no parecían hacerse preguntas sobre el destino de esos antiguos pobladores, que consideraban ajenos a su identidad o patrimonio de un pasado muy remoto. Suponían, vagamente, que el proceso de mestizaje y la aculturación los había transformado en la sociedad campesina actual" 57

Estas ideas se sostenían para las autoras, en una suerte de "laguna temporal, un tiempo de nadie, entre el pasado más remoto con el que los santamarianos no se identificaban y la historia recordada, tal vez

\footnotetext{
${ }^{56}$ Rodríguez \& Lorandi; 2005; p. 433.

${ }^{57}$ Rodríguez \& Lorandi; 2005; p. 435.
} 
Mestizaje colonial y mestizajes estratégicos. Una mirada crítica a la relación entre historia regional e historia indígena

limitada al siglo en el que vivían"58. No obstante, 30 años después, y "contradiciendo lo que se había observado en la década del sesenta, lo que primero llamó la atención fue que los pobladores de Santa María, que se autoadscribieron en primera instancia como santamarianos, constituyeron como su "otro", por antonomasia, a los pobladores del Valle de San Fernando", y en su lugar aparece una identidad arraigada en "sus tradiciones", "historias, mitos, leyendas, Pachamamas, apachetas, indios, gauchos, aparecidos, fantasmas, brujas, duendes, etc., se mezclan todos en una suerte de "teatralización» del ser santamariano, que sin ninguna duda es fuertemente mestizo" ${ }^{59} \mathrm{Y}$ en esta recomposición de las tradiciones de los santamarianos, señalan las autoras, "aparece con mucha fuerza - aunque creemos que se trata de un proceso bastante reciente - la idea de recuperar, revalorar y hasta volver al pasado indígena"60

Me interesa recuperar esta reconstrucción mínima del planteo que realizan Lorandi y Rodríguez sobre los procesos identitarios en Santa María para pensar cómo y cuáles son las características de estos procesos de transformación que van desde una identidad netamente campesina, a la problematización treinta años después, de una identidad mestiza-indígena. Las autoras, señalan dos aspectos complejos y hasta contradictorios en sus informantes del 2005. Por un lado, que si bien

se autoadscribieron como santamarianos y según ellos con características propias, bien delimitadas, también insistieron con preocupación en que la cultura del santamariano era muy mezclada, impura e inauténtica y plantearon la necesidad de volver a ser algo que ya no son, de recuperar un pasado ideal, culturalmente puro y auténtico ${ }^{61}$

Pero a su vez, también señalan que

Una de las características que apareció con más fuerza y distintividad en los discursos analizados es, contradiciendo la cristalización propuesta desde los organismos oficiales, la supuesta rebeldía de los santamarianos. Esa rebeldía es relacionada por ellos directamente con la historia colonial, en particular con la resistencia indígena que ellos suponen que los une al pasado - «esa sangre india que

\footnotetext{
58 Rodríguez \& Lorandi; 2005; p. 435.

${ }^{59}$ Rodríguez \& Lorandi; 2005; pp. 435.

60 Rodríguez \& Lorandi; 2005; pp. 435-436.

61 Rodríguez \& Lorandi; 2005; p. 436.
}

35

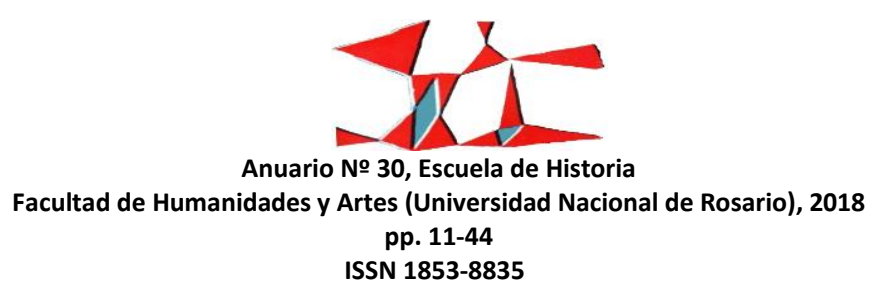


a veces nos sale»- y que por ende define o de la cual se desprenden muchas otras características: la autonomía, la independencia, la singularidad, la solidaridad. Es decir, el pasado del lugar los une a los santamarianos en una historia de rebeldías y confrontaciones, este pasado les sirve no sólo para delimitar su propia identidad, sus sentidos de pertenencia, sino que a partir de él recortan la figura del «otro» del cual se diferencian y al cual se contraponen. ${ }^{62}$

Cuando hablamos de lugares inestables de enunciación, de ambivalencia y mezclas, me refiero exactamente a este tipo de procesos identitarios. Como se puede apreciar en las citas, la idea de mezcla, convive con la de "búsqueda de un origen". El mestizaje no homogeneiza una identidad criolla, ni deshabilita la posibilidad de una "recuperación del pasado indígena", es más bien lo contrario, asumir la idea de mezcla es lo que permite reconstruir los vínculos con la herencia indígena, con ese "pasado rebelde de los santamarianos". La comparación entre las apreciaciones recogidas en la década del 60 y luego a principios de 2000, nos muestran la transformación desde una identidad más bien cerrada, anclada en lo campesino y en la identidad provincial (identificación a partir de una idea de territorio nacional); hacia una identidad con rasgos multiétnicos, con componentes campesinos, pero también míticos (leyendas, cuentos, apachetas, pachamamas y duendes), con una clara búsqueda en la herencia indígena, y con un desplazamiento de la identidad que ya no se afinca en las delimitaciones del territorio nacional (los catamarqueños pasan a ser el "otro" por antonomasia), sino que se resignifican las relaciones a partir de la geografía del Valle Calchaquí, es decir, se fortalece una identidad regional con los pueblos cercanos de Tucumán y Salta. Estas transformaciones aparecen con contundencia en los testimonios que se recogen sobre la designación de "Collas" a los santamarianos:

Esta designación, que tiene una carga peyorativa y hasta de estigma, es incorporada por los santamarianos a su patrimonio social, resignificada y exhibida a su vez como rasgo diacrítico de su identidad, según lo expresaron algunos informantes:

"La gente de San Fernando nos llaman los Collas. Ellos mismos son los que hacen las separaciones, allá los santamarianos [...] Creo que son raíces que nos van quedando de esos 130 años de guerra y de combatir, creo que eso perdura como una característica, ¿no? del santamariano, de los hombres de

\footnotetext{
62 Rodríguez \& Lorandi; 2005; p. 440.
} 
Mestizaje colonial y mestizajes estratégicos. Una mirada crítica a la relación entre historia regional e historia indígena

los valles [...]»«[En] Santa María nos caracterizamos por ser rebeldes como nos tienen los catamarqueños o como nos dicen los Collas, o sea a Ud. quizás le suena muy raro cuando decimos los catamarqueños, pero en Santa María como que no somos catamarqueños pero bueno [...] ${ }^{63}$

A este análisis sobre las transformaciones identitarias, Lorandi y Rodríguez suman además, una interesante reflexión al cruzar estos sentidos con los que promueven las instituciones y organismos oficiales de Santa María. Imposible de abordar aquí ese punto, señalo finalmente, cómo entienden las autoras este tipo de apropiaciones del pasado:

Lo emergente, en nuestro caso, son las respuestas, identidades, pasados y memorias reelaboradas, disputadas y alternativas al discurso dominante. El pasado, que es el elemento sobre el cual hicimos hincapié en este trabajo, es apropiado de diversas maneras por distintos sectores de la sociedad santamariana y por supuesto también en diferentes momentos. Esas apropiaciones no son ni más ni menos verdaderas, son simplemente diferenciales. ${ }^{64}$

Identidades diferenciales, identidades ambivalentes, identidades y procesos de identificación que desafían los esencialismos culturales e historiográficos en la forma de mestizajes estratégicos en los que coexisten múltiples universos de sentido sin reducirse unos a otros, conformando lugares de enunciación inestables y dinámicos; este es el rastreo propuesto con el que intento invitar a una lectura crítica de las historiografías regionales.

Para finalizar y terminar de dar forma a esta propuesta, veamos el segundo caso de análisis desarrollado por el antropólogo cultural y filosofo José Luis Grosso, en su imprescindible libro: Indios Muertos, Negros invisibles. Hegemonía, Identidad y Añoranza; 2008. Este autor, que realizó trabajo de campo por más de veinte años en Santiago del Estero, experiencia que recoge en el mencionado libro, parte también de una visión sumamente crítica de lo que significó el mestizaje colonial como borramiento histórico, progresivo e intencionalmente planificado:

\footnotetext{
63 Rodríguez \& Lorandi; 2005; p. 440.

${ }^{64}$ Rodríguez \& Lorandi; 2005; p. 441. Resaltado mío.
}

37

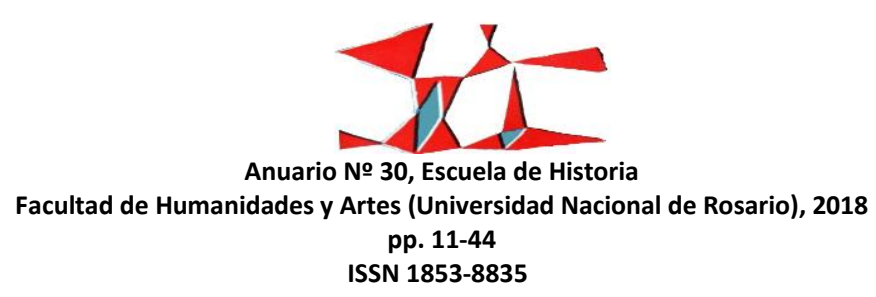


Hay una ruptura, una operación política en este borramiento, en esta aparentemente objetiva "desaparición” de aquellas categorías del uso social (las de mulato, cholo, zambo, negro e indio), por medio de la cual un nuevo modo de percepción, que blanquea los rostros oscuros, es establecido. El mestizaje creciente no ha tenido por qué conducir "objetivamente", como por el "ordena natural de las cosas", a una generalización homogeneizante en la categoría "mestizo". Mestizo, es más bien, la Nada social sobre la que se funda la historia nacional, y sobre la que se imprimirá el sello europeizante. El mestizo, en el uso social colonial, mezcla de indio y español, fue la categoría diferencial que, relativamente, más se prestaba a un blanqueamiento general del imaginario ${ }^{65}$

Como se aprecia en la cita, Grosso también liga el mestizaje a una categoría diferencial, y señala este devenir ni "objetivo", ni "natural" del mestizo, que fue políticamente planificado. Ahora bien, ¿pudo esa planificación obturar todas las posibilidades de mezcla, incluso aquellas donde ha resistido, persistido, donde reaparece lo indígena? En Indios Muertos, Negros Invisibles José Luis Grosso dedica todo un capítulo al estudio del quichua en Santiago del Estero. Me detengo en algunas consideraciones de ese capítulo. El análisis parte de, podríamos decirlo así, una larga conversación e intercambio con Armando Martínez, miembro de la comunidad indígena diaguita Calchaquí de Amaicha, afianzado hace mucho en la localidad de La Banda en Santiago del Estero, y delegado allí de la Asociación Indígena de la República Argentina (AIRA). En las actividades que realiza Antonio Martínez, los involucrados a los que él llama "indígenas", apenas aceptan identificarse como "descendientes lejanos de indios". Ante esta situación, Grosso repara en una interesante "dinámica generada por este representante de la AIRA, porque la identidad indígena se transforma en un campo de negociación y en un mapa de equívocos, entre la procura de socios explícitos por parte de la AIRA, por un lado, y la negación a verse como "indios" por parte de los habitantes mesopotámicos, por el otro"66. Las actividades de recuperación de las comunidades indígenas, y la certeza de su existencia, se anclan, tanto para la AIRA como para Martínez en el hecho de que se hable quichua. Incluso, dando cuenta y recuperando testimonios de este delegado en distintas actividades, Grosso marca que es solo el ser quichua-hablantes lo que convierte a los sujetos en "representantes" de la identidad indígena. En torno a la lengua, gira entonces el problema y la búsqueda:

65 Grosso; 2008; p. 55. Resaltado mío.

66 Grosso; 2008; p. 77. 


\section{Mestizaje colonial y mestizajes estratégicos. Una mirada crítica a la relación entre historia regional e historia indígena}

el quichua y el miedo son los dos polos explicativos para Armando Martínez de por qué en Santiago del Estero no hay indígenas explícitos. Un miedo fundado en la discriminación, la prohibición, la humillación. Por eso, Armando Martínez somete a una terapia lexical los términos que han operado políticamente en la execración de la identidad indígena en la Colonia y su negación en la República: indio, raza..." ${ }^{\prime 67}$

Este miedo, esa vergüenza, es una constante al día de hoy, sobrados ejemplos de primera mano me lo han corroborado ${ }^{68}$. La asunción explicita y pública de la identidad indígena en Argentina, sigue siendo un

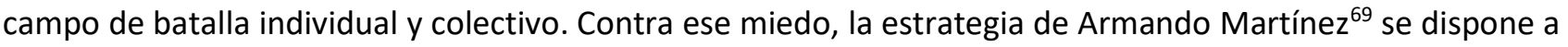
remontar "yendo por detrás de la elocuencia quichua, la negación de lo indio en la Mesopotamia santiagueña, hasta reencontrar su positividad". Pero al miedo, se le suma, lo acompaña otro gesto, el silencio. Martínez lo señala como la mayor dificultad: "Ios hermanos de Santiago lo que tienen es el silencio. Sacarles una palabra...".

Entonces, negación, miedo y silencio, es el escenario de la identidad negada de lo indígena en Santiago. No obstante, Grosso no cierra aquí su análisis, sino que más bien lo inicia,

el silencio es vivenciado como enemigo por las políticas de la lengua y la identidad de Armando Martínez. Pero en ese silencio puede haber no solo miedo, sino también maquinación resignificadora, un espacio de prácticas silenciosas que transfiguran lo "Indio" y lo sostienen en el campo social, sin hacerlo verbalmente explícito ${ }^{70}$

En esta línea, Grosso pone bajo análisis una larga lista de "tácticas bilingües ${ }^{71}$ " que se dan en la Mesopotamia santiagueña. Esa lista recorre interesantes y complejos entramados donde se diferencia un registro de la quichua doméstico y femenino, otro registro de la quichua campesino, otro registro de la

67 Grosso; 2008; p. 79.

68 Recuerdo, un caso en un encuentro de docentes de EIB en Nazareno, Salta, donde una joven egresada, mencionaba que solo a través de su identidad docente y gracias a ella, había podido asumir públicamente su identidad colla. Sus palabras, con las variaciones del tiempo y la memoria, fueron las siguientes: "la primera vez que me asumí colla, fue como docente colla, en un aula".

${ }^{69}$ El texto cuenta con extensas entrevistas y explicaciones del propio Martínez, imposible de recuperar en este trabajo, pero que cuenta con una riqueza extraordinaria.

70 Grosso; 2008; p. 85.

${ }^{71}$ Tengamos en cuenta que para el año 1992 se registraban unos 80.000 bilingües quichua/español en la Mesopotamia santiagueña. 39

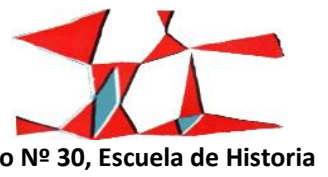

Facultad de Humanidades y Artes (Universidad Nacional de Rosario), 2018

pp. 11-44

ISSN 1853-8835 
quichua urbana (negada y silenciada), un registro de la castilla distinto del español, un registro de EI quichua, institucional, urbano y formal, que conviven conflictivamente. Pondré a consideración solo uno de estos registros de tácticas bilingües para pensar nuestra idea de mestizajes estratégicos, el de los quichuistas urbanos. Dentro de estos, Grosso identifica dos grupos, uno "que se ha movido fundamentalmente en el ámbito académico, y de formación de maestros; el otro se ha expandido más entre los quichua-hablantes, teniendo como su vehículo de circulación principal, la música. El primero promueve un quichua "culto"; el segundo, "la quichua"”" (Grosso, 2008, p. 97). Dentro del primero se destaca la figura de Domingo Bravo, y se puede mencionar la creación en 1975 de la Cátedra de Lingüística Regional Quichua-Castellano en la UNSE. En el segundo grupo podemos destacar desde 1969 la figura de Sixto Palavecino y de la fundación del "Alero Quichua Santiagueño", que surge asociado a un programa radial72 de los más escuchados en los domingos santiagueños, transmitidos por LV11 en aquella época y luego por Radio Nacional de Santiago del Estero. Del análisis sobre estos grupos, Grosso se detiene en la manera en que ambos se posicionan frente al Quinto Centenario de 1992, ese es el punto central que quiero recuperar.

De los quichuistas académicos, dice Grosso:

En 1992, año del Ilamado Quinto Centenario del "Descubrimiento" de América, en las Primeras Jornadas de Lingüística Aborigen, organizadas por la Facultad de Filosofía y Letras de la Universidad de Buenos Aires, se declaró, a propuesta del mismo Domingo Bravo, al quichua santiagueño el "Quichua Argentino".

(...) ¿Es tomada como "lengua aborigen" de un "aborigen muerto"? Peculiar inclusión, llena de tortuosas torsiones, esta, la del quichua argentino, en unas Jornadas de Lingüística Aborigen con ocasión del Quinto Centenario del "Descubrimiento" de América ${ }^{73}$

¿Cómo pensar estas torsiones? ¿Qué decir de ellas en relación a la reconstrucción de las identidades indígenas, de los imaginarios histórico-raciales de nuestra nación? ¿Qué decir de estos académicos que "ni

\footnotetext{
72 Es un programa bilingüe al que concurren en gran cantidad los músicos del interior, teniendo de ese modo la oportunidad de ser oídos por una gran audiencia. De hecho varios grupos han surgido al reconocimiento social por este medio. El programa ha desencadenado durante todos estos años, entre músico y oyentes, una intensa dinámica regional. Al comienzo de cada sesión, Sixto Palavecino saluda en la quichua.

73 Grosso; 2008; p. 98.
} 


\section{Mestizaje colonial y mestizajes estratégicos. Una mirada crítica a la relación entre historia regional e historia indígena}

siquiera quieren ser lejanamente confundidos, con “indios"? Según lo planteado aquí, este tipo de posturas, bien podrían leerse en los términos de las lógicas de inclusión-negación que plantea Muyolema y de las falacias de las múltiples herencias culturales. Grosso señala lo mismo, pero más focalizado en la cuestión de la hegemonía y la nación, para él, el "quichua argentino":

Es una clara estrategia de nacionalización y de construcción de una hegemonía santiagueña a nivel idiomático (...)

El quichua es nacionalizado, se lo coloca como lengua viva en un lugar subalterno respecto de la hegemonía nacional, aquella que ha hecho desaparecer a los "Indios" quichua-hablantes de Santiago del Estero ${ }^{74}$

Mestizaje colonial en la lengua por un lado, y nacionalizaciones vigentes en pleno siglo XX, por el otro. Ambas operando bajo lógicas hegemónicas no ya, de la torpeza ideológica del blanqueamiento, sino de procesos mucho más finos que articulan reivindicaciones lingüísticas indígenas (formales-urbanas), al mismo tiempo que subalternizan los idiomas y usos campesinos y domésticos de los propios hablantes-indígenas.

Pero he dicho que en estas tácticas bilingües me interesaba rastrear un tipo de mestizaje estratégico, y para ello, debemos prestar atención a lo realizado por el segundo grupo de quichuistas urbanos frente al Quinto Centenario. Para el 23a aniversario del Alero, año del mismo Quinto Centenario, se realizó por primera vez, en la Catedral de Santiago, el rezo de la Misa en Quichua Santiagueño, y además, el Alero organizo una semana de festejos, sugestivamente, del 5 al 11 de octubre, es decir, una semana antes del 12 de octubre, día del descubrimiento de América. El lema para la ocasión fue Ashpay Llijchay: “Despierta, tierra mía”75 En la transmisión radial de ese domingo, realizada desde la Plaza Libertad, la central de la ciudad de Santiago, Sixto Palavecino leyó un poema compuesto para la ocasión denominado "Día de la Raza":

Pischka pachaj huatas chayan Quinientos años llegan, Ishcay huarencka atin cayta dos mil pueden ser,

\footnotetext{
${ }^{74}$ Grosso; 2008; pp. 99-100.

75 Grosso; 2008; p. 100.

41

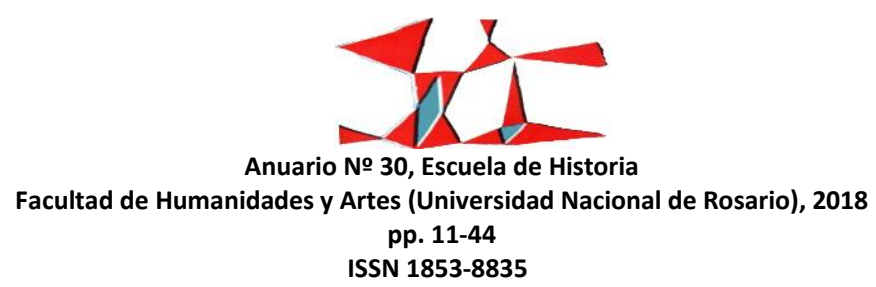


Imaynataj ckoncka suychis

Huaucke suiyshta y tatarisyshta ¿cómo todos nosotros aguardamos el olvido a nuestro hermano que espera con cariño y a nuestro siempre querido padre?

"antes que doce de octubre,

así dice un cualquiera,

"el día de la raza dicho aquí,

yo digo el once no más" ${ }^{76}$

Sobre este peculiar acto, el antropólogo y filósofo reflexiona lo siguiente:

"estamos ante el discurso contestatario indígena americano en contra de los festejos del 12 de octubre, que determina el día anterior, el 11, como Día de los Pueblos Indígenas, justamente antes de la invasión europea con sus masacres. El discurso es en lengua indígena y se recuerda a los antepasados, sin reconocerse étnicamente. Pero no cabe duda de que el enunciante ocupa el lugar del indígena, ritualmente, en un gesto de culto a la memoria. Don Sixto aquí habla desde el lugar del "indio" y con su lengua ${ }^{77}$

Lugar inestable por excelencia, la enunciación de Don Sixto se inscribe en una multietnicidad estratégica, en un mestizaje estratégico, que le permite recuperar el quichua para las identidades campesinas no hegemónicas contra el quichua institucional y formal, que le permite dar lugar a la identidad de aquellos bilingües que no se consideran "indios" pero que construyen sus identidades colectivas en la quichua, a la memoria de los "antepasados" por todos reconocidos, a la tradición de lucha anticolonial y antinacional, a las identidades populares del folklore y sus siempre ambivalentes herencias culturales afro e indígenas. Dice, finalmente Grosso:

76 En el texto de Grosso pueden encontrarse varias aclaraciones sobre la traducción del poema, referencias sobre los usos de algunas expresiones y sobre la particular manera en que el mismo fue expresado oralmente por Don Sixto. Grosso; 2008; pp. 100103.

77 Grosso; 2008; p. 102. 
Mestizaje colonial y mestizajes estratégicos. Una mirada crítica a la relación entre historia regional e historia indígena

Es en el quichua santiagueño donde el "indio" mesopotámico construyó su lengua, en el marco de una "alienación inalienable"78, la alienación constitutiva de usar la lengua del "otro", impuesta, ya sea por el Incario o por la Corona española, pero poniendo/acogiendo/reapropiando/remarcando en ella las marcas en las que se establece una nueva subjetividad. Lengua ajena, el quechua, sobre la cual ese otro dominante tampoco tenía propiedad: se la había apropiado para imponerla. Y así, hacia atrás en la historia, vemos cómo lenguas impuestas se han vuelto lenguas reapropiadas. En cada nuevo contexto de las políticas de la lengua, el quichua ha desarrollado nuevas batallas ${ }^{79}$

Reapropiación, esa es la idea que ata los textos de Lorandi y Grosso, reapropiación de un pasado en el primer caso, reapropiación de una lengua en el segundo. Disputas por el presente, por la complejidad de los procesos vividos por las sociedades indígenas a lo largo de más de cinco siglos de interacciones étnicas, políticas y culturales, de luchas, de resistencias, de colonialismo español y colonialismo-nacional; más de cinco siglos de PERSISTENCIA en la construcción de una identidad, ni pura ni mestiza, propia e histórica.

Finalmente, el objetivo de este recorrido, no son las categorías propuestas de mestizaje colonial y mestizaje estratégico, ni las de multietnicidad y relaciones interétnicas, ellas son el medio, la excusa, para el sentido real de este trabajo que es poner en el centro de las disputas actuales sobre la historia y los imaginarios histórico-raciales, la siguiente pregunta: ¿Es posible, hoy, hacer historia regional, historia indígena o historia nacional, sin dar cuenta y problematizar los complejos procesos de transformación identitarios-políticos-culturales y sociales de los pueblos indígenas?

\section{Bibliografía:}

Bazán, Raúl Armando; Historia del Noroeste Argentino; Ed.; P. Ultra; Buenos Aires; 1995.

Grosso, José Luís; Indios Muertos, Negros Invisibles. Hgemonía, Identidad y Añoranza; (1era ed.); Encuentro Grupo Editor; Córdoba; 2008.

\footnotetext{
78 Derrida; 1997

79 Grosso; 2008; p. 100. Resaltado mío
}

43

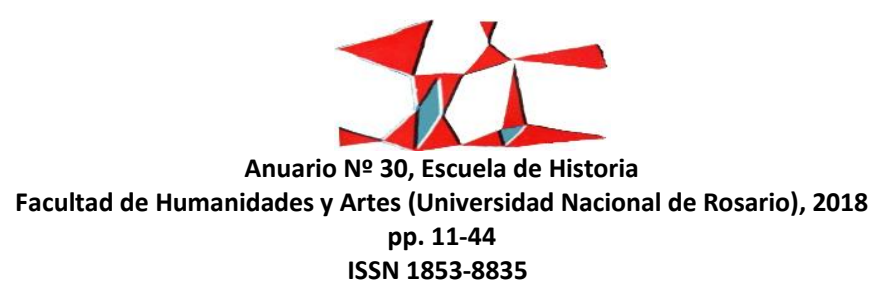


Lorandi, Ana María; El mestizaje interétnico en el noroeste argentino; Senri Ethnological Studies; 33; p. 133$166 ; 1992$.

Muyolema-Calle, Armando; Colonialismo y representación. Hacia una re-lectura del latinoamericanismo, indigenismo y de los discursos clase-etnia en los andes del Siglo XX; University of Pittsburg; Retrieved from; 2007.https://search.proquest.com/openview/03aa6f87b0243336665a7122b860c71c/1?pq-

origsite $=$ gscholar $\& \mathrm{cbl}=18750 \&$ diss $=y$

Muyulema, Armando; De la "cuestión indígena"a lo "indígena"como cuestionamiento. Convergencia de Tiempos: Estudios Subalternos/contextos Latinoamericanos. Estado, Cultura Y Subalternidad; GA; Rodopi; Ámsterdam/Atlanta; 2001

Rodríguez, Lorena B., \& Lorandi, Ana María; Apropiaciones y usos del pasado. Historia y patrimonio en el valle Calchaquí; Bulletin de I'Institut Français D'études Andines; (34 (3); p 431-442; 2005.

Tieffemberg, Silvia; Lugares de enunciación inestables. Telar: Revista Del Instituto Interdisciplinario de Estudios Latinoamericanos; 9 (11); p. 269-283; 2013.

Recibido: 31 de julio de 2018 Aceptado: 27 de septiembre de 2018 Versión Final: 26 de octubre de 2018 